\title{
Honeywell
}

\section{Evaluation Of Automated Low-Field Nuclear Magnetic Resonance (NMR) Relaxometry For Analysis Of Silicone Polymers}

Federal Manufacturing \& Technologies

M. H. Wilson

KCP-613-8630

Published September 2009

Final Report

Approved for public release; distribution is unlimited.

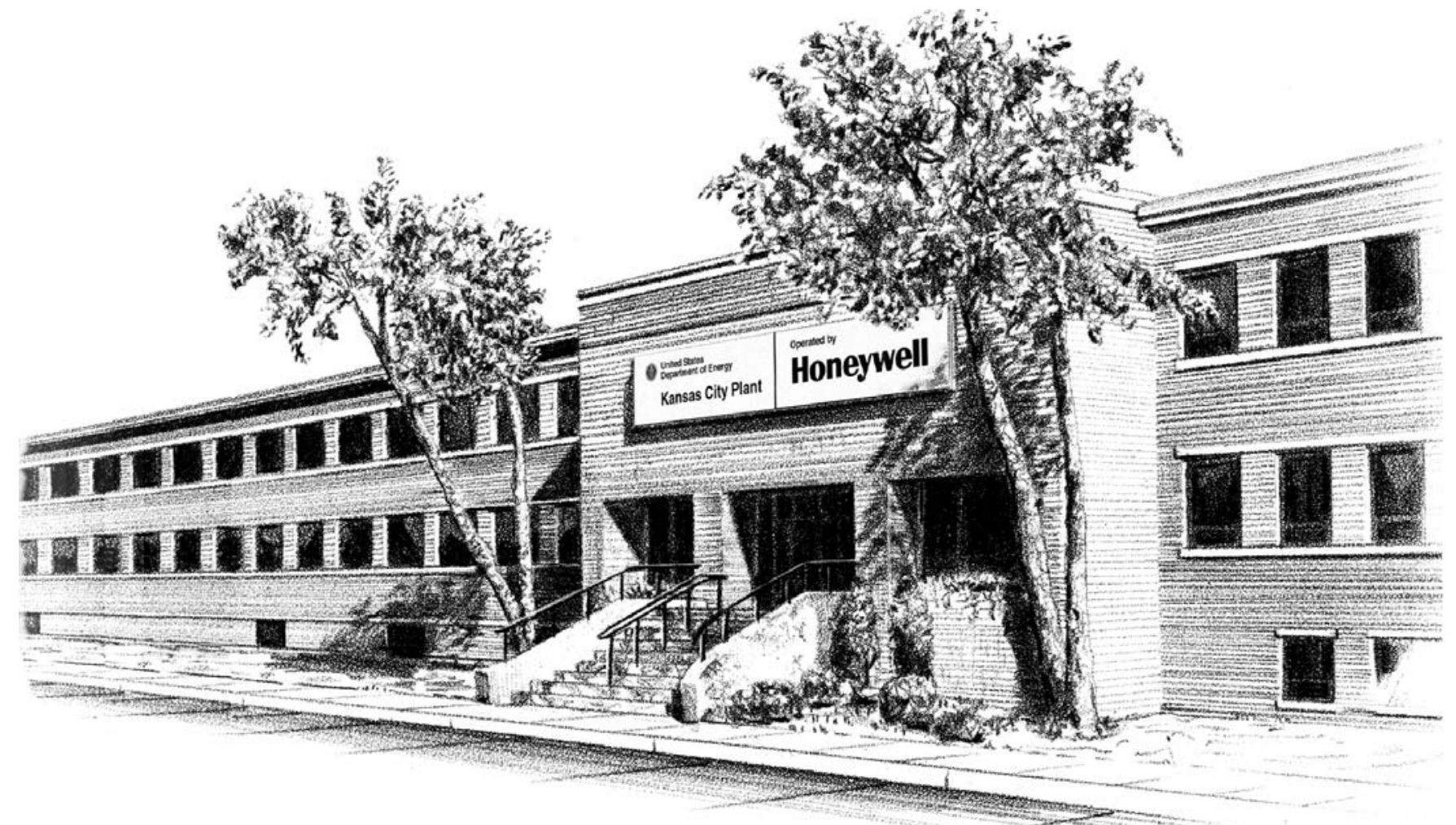




\section{DISCLAIMER}

This report was prepared as an account of work sponsored by an agency of the United States Government. Neither the United States Government nor any agency thereof, nor any of their employees, makes any warranty, express or implied, or assumes any legal liability or responsibility for the accuracy, completeness, or usefulness of any information, apparatus, product, or process disclosed, or represents that its use would not infringe privately owned rights. Reference herein to any specific commercial product, process or service by trade names, trademark, manufacturer, or otherwise, does not necessarily constitute or imply its endorsement, recommendation or favoring by the United States Government or any agency thereof. The views and opinions of authors expressed herein do not necessarily state or reflect those of the United States Government or any agency thereof.

All data prepared, analyzed and presented has been developed in a specific context of work and was prepared for internal evaluation and use pursuant to that work authorized under the reference contract. Reference herein to any specific commercial product, process or service by trade name, trademark, manufacturer, or otherwise, does not necessarily constitute or imply its endorsement, recommendation or favoring by the United States Government, any agency thereof or Honeywell Federal Manufacturing \& Technologies, LLC.

Printed in the United States of America.

This report has been reproduced from the best available copy.

Available to DOE and DOE contractors from the Office of Scientific and Technical Information, P.O. Box 62, Oak Ridge, Tennessee 37831; prices available from (865) 576-8401, FTS 626-8401.

Available to the public from the National Technical Information Service, U.S. Department of Commerce, 5285 Port Royal, Rd., Springfield, Virginia 22161, (703) 487-4650.

A prime contractor with the United States Department of Energy under Contract Number DE-AC04-O1AL66850

\author{
Honeywell Federal Manufacturing \& Technologies \\ P.O. Box 419159 \\ Kansas City, Missouri, 64141-6159
}




\title{
Honeywell
}

KCP-613-8630

Distribution Category UC-42

Approved for public release; distribution is unlimited.

Evaluation Of Automated Low-Field Nuclear Magnetic Resonance (NMR) Relaxometry For Analysis Of Silicone Polymers

\author{
M. H. Wilson \\ Published September 2009 \\ Final Report \\ M.H. Wilson, Project Leader
}





\section{Contents}

Section Page

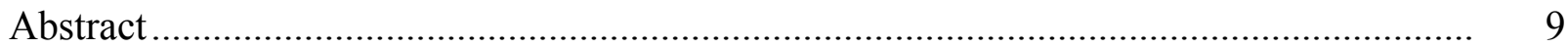

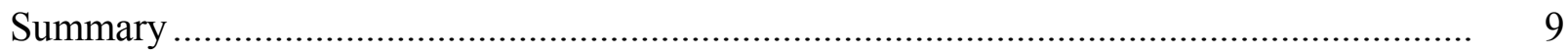

Discussion ............................................................................................... 11



Prior Work ........................................................................................ 11

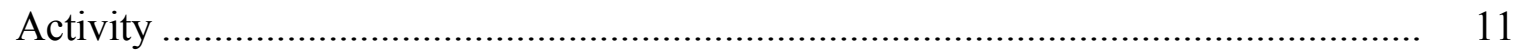

Background ........................................................................................... 11

Simulated Data and Measurement Methodology ............................................. 15

DoE for Comparison of Metal Versus

Plastic Chamber Struts .............................................................................. 17

Outliers and Anomalies ...................................................................... 18

Repeatability Study Results With Plastic Parts .............................................. 22

DoE Result Comparing Effect of Replacing

Surveillance Versus New OPPs ................................................................. 30

Cellular Silicone Parameter DoE .................................................................. 33

Cellular Silicone Measurement Results ....................................................... 37

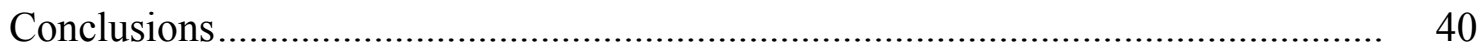

Accomplishments ................................................................................... 41

Future Work ........................................................................................... 41

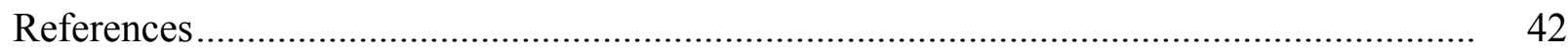




\section{Illustrations}

Figure Page

1 Minispec NMR and Automated System ...................................................... 12

2 The Minispec ProFiler Measurements Show

a Correlation Between Increasing $\mathrm{T}_{2}$ Values

With Increasing Levels of Peroxide.

3 Solvent Swell and Physical Property Correlation

With Peroxide Level and Measured $\mathrm{T}_{2}$ Values.

4 OPP Measurement Locations with Metal

Support Struts on Left

5 Simulated Data of Rotating or Flipping OPP.

6 Plots Showing Bi-modal Distribution With Study

22 and Other Outliers Separated From the

Other Studies

$7 \quad \mathrm{~T}_{2}$ Error Bi-Modal Distribution Showing

7,224 Outliers as Unbolded Symbols

8 Graphs on the Right Show the Data Set Remaining

After Omitting 8,155 (19.7\%) Outliers

9 Repeatability Study Measurements

With Outliers Omitted.

10 Repeatability Study Measurement of OPP

1 in Position A with Outliers Omitted

11 Repeatability Study Measurements of OPP

2 in Position B With Outliers Omitted..

12 Repeatability Study Measurements of OPP

3 in Position C with Outliers Omitted...

13 Repeatability Study Measurements of OPP

4 in Position D With Outliers Omitted

14 Repeatability Study Measurements of OPP 5 in Position E With Outliers Omitted 
15 Repeatability Study Measurements of OPP

6 in Position F with Outliers Omitted...................................................................... 24

16 Repeatability Studies With Outliers

Omitted Showing Average Values

And Relationships

17 Noise Correlation With Chamber Location

for all OPPs Showing Reduction in Noise

at Position A After Replacing Metal

Struts with Plastic Struts.................................................................................. 25

18 Noise Correlation for all OPPs in Chamber............................................................... 26

19 Results for all OPP Property Averages

By OPP Location in Chamber..

$20 \mathrm{~T}_{2}$ Correlation for all OPPs in

all Locations in Chamber by Study .................................................................... 28

$21 \mathrm{~T}_{2}$ Correlation for all OPPs in

all Locations in Chamber by Study.

$22 \mathrm{~T}_{2}$ Correlation for all OPPs in all Locations in Chamber by OPP.

23 Correlation for all OPPs in

Location A in Chamber..

24 Correlation for all OPPs in

Location A in Chamber...

$25 \mathrm{~T}_{2}$ Values for all OPPs in

Location A With Outliers Omitted

26 Correlation of Average $\mathrm{T}_{2}$

$\pm \sigma$ With Age for New and

Surveillance OPPs.

27 Response Results for Cellular

Silicone Parameter DoE.

$28 T_{2}$ Response Results for Cellular

Silicone Parameter DoE. 
$29 \mathrm{~T}_{2}$ Response Results for Cellular

Silicone Parameter DoE

30 Cellular Silicone Sample Between

ProFiler and the OPPs Polyethylene

Centering Fixture

$31 \mathrm{~T}_{2}$ Value Contour Plot of Cellular

Silicone Sample Showing Edge

Effects for Scan Pattern in Graph

on Right.

32 Circle Shows the Location of the

Cellular Silicone Sample

33 Plots of Various Minispec Response

Variables for Locations in Figure 32

\section{Tables}

Number

Page

1 Location of OPP by Number Within

Chamber for DoE With Metal Parts.

2 Location of OPP by Number Within

Chamber for DoE, Repeatability Study, and

Comparison to Surveillance OPPs with Plastic Parts

18

3 Details of DoE for Parameter Optimization. 


\begin{abstract}
Screening studies and Design of Experiments (DoE) were performed to evaluate measurement variation of a new, non-destructive Nuclear Magnetic Resonance (NMR) test system designed to assess age-induced degradation of Outer Pressure Pads (OPP). The test method and results from 54,275 measurements are described. A reduction in measurement error was obtained after metal support struts were replaced with plastic support struts adjacent to the front position of the test chamber. However, remaining interference and a lack of detecting any age-related degradation prevent the use of the NMR system as a non-destructive surveillance test for OPPs. A cursory evaluation of the system with cellular silicone samples obtained more uniform results with increased error as measurements approached the sample's edge.
\end{abstract}

\title{
Summary
}

New surveillance tests are being evaluated to improve diagnostics on aged polymer cushions and pads of Lawrence Livermore National Laboratory (LLNL) systems. A novel instrument has been designed using Nuclear Magnetic Resonance (NMR) coupled with automated data collection. A prototype has been installed at the Kansas City Plant (KCP) to evaluate its use for surveillance testing. The minispec ProFiler determines the ${ }^{1} \mathrm{H}$ NMR spin echo time constant, $\mathrm{T}_{2}$, which provides an indirect measure of average crosslink density as an indicator for extent of degradation with age.

Previous tests of the new system identified anomalous random noise in measurements, variance in curve fits, and possible error caused by a nearby metal component adjacent to measurement locations within the chamber [1]. The results indicated that a metal support strut adjacent to the front position in the chamber interferes with the measurements and there is a measurement property gradient from the front to the back of the chamber. Recommendations from a previous Design of Experiment (DoE) have been completed that replaced metal parts with plastic parts. The DoE was repeated to determine the effectiveness of the new plastic parts to reduce measurement variation. 41,472 measurements were taken during various screening tests and the repeated DoE. The results showed that replacing the metal parts with plastic parts had a strong effect and eliminated the major noise interference patterns observed in the previous DoE study. However, the level of variation is still relatively large and now indicates a property gradient in certain measurements from the left side to the right side of the chamber.

An additional 12,803 measurements were taken on surveillance Outer Pressure Pads (OPPs) and a cellular silicone sample. The ProFiler was not able to distinguish recently molded OPPs from surveillance-returned OPPs. This and other experimental variation limits the instrument's capability to primarily detecting combinations of large internal voids or grossly undercured areas that contain $<50 \%$ of the recommended catalyst level. More importantly, whereas the ProFiler can detect large differences in crosslink density in flat slab samples, it appears the level of agerelated changes in OPP crosslink density has not progressed enough, and are below the detection limit of the present configuration. Thus, the ProFiler, in its current configuration, is not recommended for use as a non-destructive surveillance test method for the OPPs. 
The ProFiler may still be a suitable tool for other types of material, and results on a cellular silicone sample showed good repeatability considering the larger, more uniform sample thickness and after eliminating known adverse edge effects. Significant challenges would have to be overcome to measure samples with curved surfaces or unusual shapes in order to mitigate the kind of variation seen in these studies due to non-uniform amounts of material in the measurement field based on the sample area's relative proximity to the ProFiler's surface. 


\section{Discussion}

\section{Scope and Purpose}

Evaluate new surveillance methods based on NMR testing to improve diagnostics on polymer cushions and pads of LLNL systems. Because OPP production plans were halted with the cancellation of the weapons project, the scope was modified to develop this test for surveillance OPP diagnostics and other applicable materials, accomplished through the installation and validation of the minispec ProFiler at KCP.

\section{Prior Work}

This report updates work previously reported and documents the results of replacing metal parts with plastic parts on the automated measurement system [1].

\section{Activity}

\section{Background}

In order to improve diagnostics on polymer cushions and pads of LLNL systems, new surveillance tests are being evaluated to detect crosslink density changes with age. A new test method has been developed and validated based on a unique system design using static, uniaxial NMR relaxometry coupled with automated data collection [2]. A prototype system has been installed at $\mathrm{KCP}$ to evaluate its use for surveillance testing.

The prototype installed at KCP comprises an automated system that was developed with Bruker Optics, Inc., (The Woodlands, TX) to allow multiple measurements without operator intervention. The magnet of the minispec ProFiler is mounted to a modified commercial Autosampler (Duratech, Waynesboro, VA) and controlled via an attached PC for automated measurements (Figure 1). Large numbers of manual sample measurements with the ProFiler are impractical and also are prone to measurement error because of variation in placement of the probe during repeated measurements. The precise control offered by the automated system greatly minimizes this variation.

An enclosure (metal honeycomb box) also was constructed to contain the entire system and block possible electromagnetic interference (EMI). Testing with and without the enclosure showed no effect within the local room environment. Nevertheless, the equipment is operated within the enclosure as a precautionary measure. 


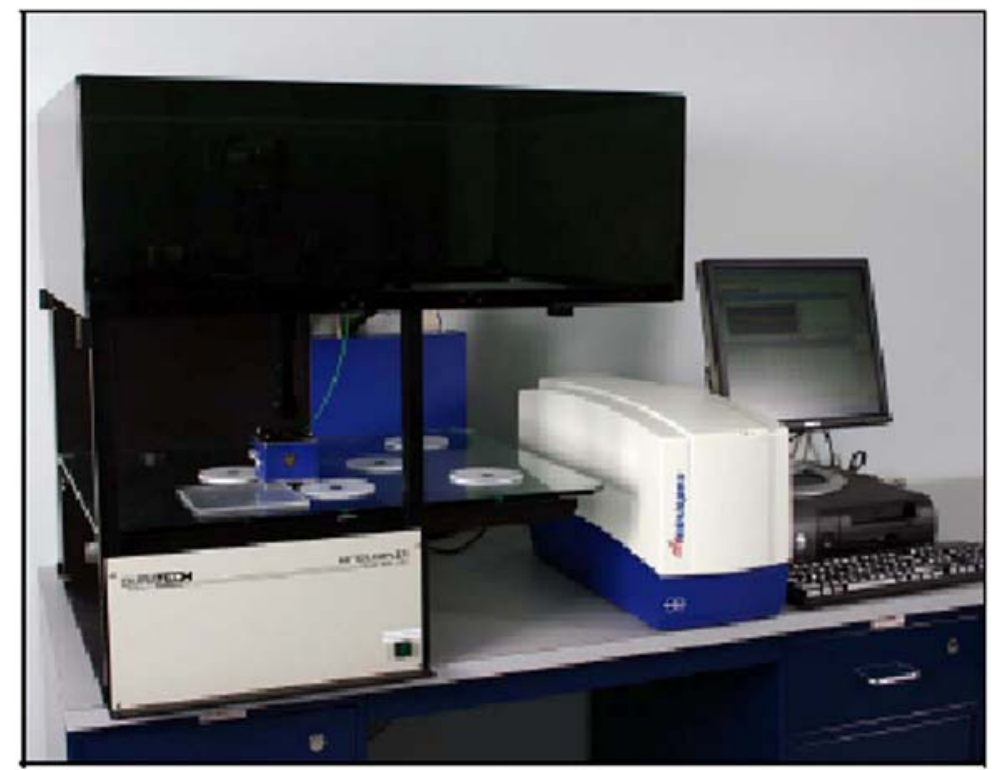

Figure 1. Minispec NMR and Automated System (Note: EMI enclosure is not shown.)

The measurements are performed using spin-echo decay curves obtained via a Carre-PurcelleMeiboome-Gill (CPMG) pulse sequence [3] with the minispec ProFiler operating at 16 megahertz $(\mathrm{MHz})$. The ProFiler determines the ${ }^{1} \mathrm{H}$ NMR spin echo time constant $\left(\mathrm{T}_{2}\right)$, which provides an indirect measure of average crosslink density [4]. The dimensions of the ceramic measurement window on the ProFiler are 53 by 20 millimeters $(\mathrm{mm})$.

Previous DoE work determined the relationship between instrument parameter settings, material properties, and resulting $\mathrm{T}_{2}$ values. The optimized parameter settings were: gain $=115$, echo time $=0.5$, number of echoes $=500$, recycle delay $=1.0 \mathrm{sec}$. These settings were used for characterization studies on Dow Corning DC745 silicone test slabs (approximately 6 x 6 x 0.075 inch) molded with various peroxide curative levels ( $0 \%$ to $175 \%$ of recommended level). Typically, increasing $\mathrm{T}_{2}$ values correlate with lower crosslink density because of the greater time scales involved for reduced crosslink regions to return to equilibrium. However, for the material samples in these studies, increasing $\mathrm{T}_{2}$ values correlate with higher crosslink density (Figure 2). Physical properties dependent on crosslink density such as solvent swell (toluene) and tensile/elongation also were found to correlate with the $\mathrm{T}_{2}$ results for these samples (Figure 3 ). This behavior is counterintuitive and possible explanations have been offered for the difference with high-field NMR observations; e.g., influence and detection of unique sample effects only at the surface versus the bulk [5]. These samples reveal that significant quantities $(<50 \%)$ of catalyst must be left out or a very inhomogeneous mix of the DC745/peroxide system must occur before noticeable changes are detected with $\mathrm{T}_{2}$. 



Figure 2. Minispec ProFiler Measurements Show a Correlation Between Increasing $T_{2}$

Values With Increasing Levels of Peroxide, i.e., Average Crosslink Density That Reaches a Maximum Upon full Cure of the Available Reactive Sites (graph on left).

Peroxide level is shown as a percent of recommended level. Also, a general increase in $T_{2}$ with thicker areas of the test slab is indicated showing a sensitivity to amount of material in the measurement field (contour plots on right).

$\mathrm{T}_{2}$ measurements were found to be sensitive enough to distinguish which mold cavity was used and also to show a general correlation with thickness (Figure 2). Thus, it was discovered that the $\mathrm{T}_{2}$ values obtained not only correlate with crosslink density, but also with the amount of material in the detection volume (i.e., material bulk density reduced by thickness, voids, gaps, etc.).

Consequently, lower $\mathrm{T}_{2}$ values in damaged areas of OPPs may be confounded with the quantity and/or spatial morphology of the damaged areas. These damaged areas may contain less material or a redistribution of material that reduces $T_{2}$ relative to adjacent, undamaged areas. More study is needed to confirm this effect and to understand the relative contribution from lower crosslink density versus material distribution within the ribbed areas of the OPP. 



Figure 3. Solvent Swell and Physical Property Correlation With Peroxide Level and Measured $\mathrm{T}_{2}$ Values. Peroxide level is shown as a percent of recommended level.

Other prior work focused on rotating OPPs beneath a stationary ProFiler and also on determining the proper orientation alignment of the magnet over the OPP during motion control by the Autosampler. Subsequent screening tests identified anomalous random noise in measurements, variance in curve fits to determine $\mathrm{T}_{2}$, and measurement error caused by nearby metal struts adjacent to arbitrarily assigned measurement locations within the chamber [1]. Results of a DoE lead to replacing three metal support struts that contributed to measurement interference with polyethylene parts (Figure 4). The DoE was repeated using the same OPPs to evaluate the effects of the plastic parts on $\mathrm{T}_{2}$ measurements. 

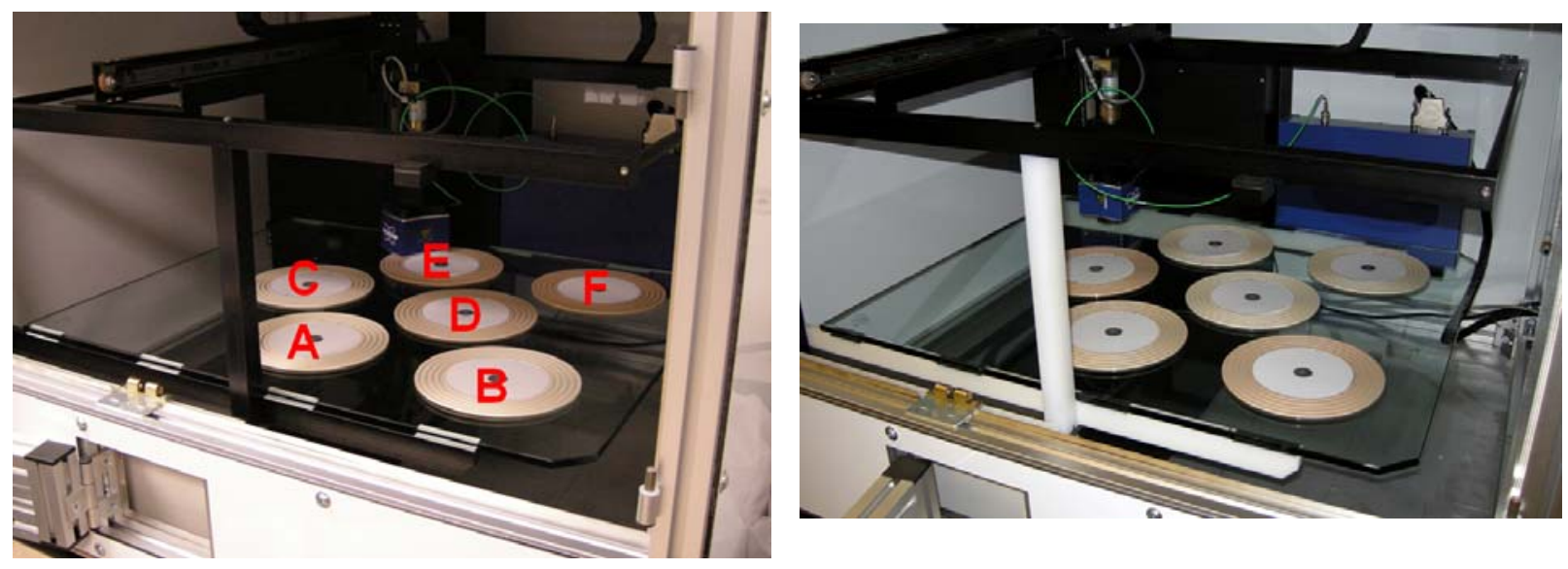

Figure 4. OPP Measurement Locations With Metal Support Struts on Left. Photograph on right shows plastic replacement parts (white) installed in front and back of measurement chamber. EMI enclosure is shown with front doors removed.

\section{Simulated Data and Measurement Methodology}

OPPs are marked at a single reference location by an ink pen with a + mark on the outer rib. $T_{2}$ is measured in $5^{\circ}$ increments counterclockwise around the OPP at radiuses centered over the gaps at $62,69,77$, and $84 \mathrm{~mm}$. An idealized data set shows the difference in $\mathrm{T}_{2}$ values after simulated measurements of an OPP for three conditions (Figure 5):

1. The black symbol ( () shows the baseline position with the + mark at 12:00 position on the OPP (i.e., away from the front of the chamber).

2. The blue symbol (/) shows measurements after turning the OPP by $180^{\circ}$ (i.e., the + mark is at the 6:00 position on the OPP placing it closest to the front of the chamber).

3. The red circle (o) shows measurements with the + mark in the 12:00 position on the OPP away from the front of the chamber and then flipping the OPP upside down (i.e., with the ribs contacting the glass).

An OPP (1) was measured in the baseline position and then these individual data measurements were assigned to be the same after rotating or flipping the part, thus assuming that there is no external interference on the measurements. With no interference (or experimental error), the three curves are identical in the top plot and represent the unrealistic goal of the measurement system to be exactly repeatable and thereby independent of OPP orientation. 

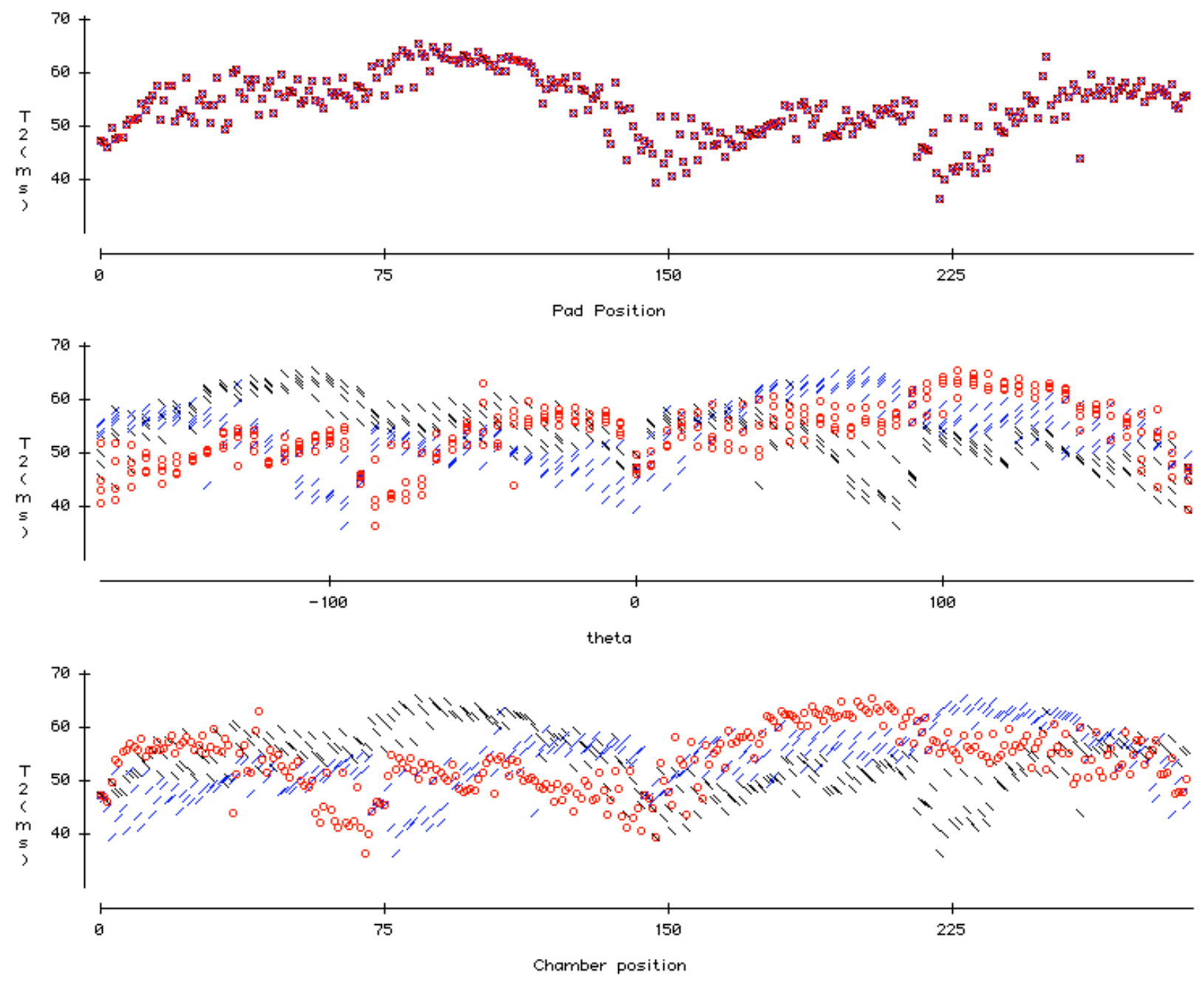

Figure 5. Simulated Data of Rotating or Flipping OPP. (Units for $T_{2}$ are $m s$ )

Pad Position denotes the sequential measurement locations on the OPP starting with position 0 at 12:00 at a radius of $62 \mathrm{~mm}$. The minispec moves radially out from the inner gap at 62 to 69,77 , and $84 \mathrm{~mm}$ and then moves counterclockwise $5^{\circ}$ repeating this sequence while incrementing the number locations from 0 to 287 . The middle plot shows the $\mathrm{T}_{2}$ values versus theta angle position around the OPP. Theta is the ProFiler rotational angle relative to the chamber with theta $=0^{\circ}$ at 12:00, (i.e. back of chamber), theta $=-90^{\circ}$ at 9:00, theta $=180^{\circ}$ at 6:00, (i.e., front of chamber) and theta $=90^{\circ}$ at 3:00. At angle theta $=0$, the Pad Position is location 0 and the + mark is farthest away from the front of the chamber. Chamber positions are the locations relative to the chamber at the theta measurement angle, as if the OPP were sitting in the chamber with locations marked on the glass.

If the data is independent of relative chamber position, then data measurements should have relatively low variability and have an appearance similar to the top plot where the data reasonably lies on top of each other after the described rotations. Furthermore, plotting data by chamber position or theta helps to identify areas that are more or less sensitive to variation due to relative location within the chamber. 


\section{$\underline{\text { DoE For Comparison of Metal Versus Plastic Chamber Struts }}$}

DoE evaluations of the robotics chamber were performed to determine the effects of the local environment on the NMR measurement repeatability before and after installation of plastic struts at the front and back of the chamber. A prior study [1] has been repeated after replacing the metal parts with plastic parts. The DoEs were designed to map all of the OPP locations in the chamber by measuring six individual OPPs in each of the six measurement locations to determine if there is a neutral measurement area unaffected by OPP position (Tables 1 and 2 and Figure 4). The Autosampler was programmed to record 288 measurements in $5^{\circ}$ increments around the OPP centered over the gaps between the ribs at radial distances of $62,69,77$, and 84 $\mathrm{mm}$. Three replicates were measured per condition $(288 \times 3=864$ measurements per OPP $)$ comprising 31,104 measurements for the complete DoE. In addition, a repeatability study (Table 2 studies 22-24) was performed by measuring one of the DoE conditions two extra times for a total of 41,472 measurements for testing the effects of the plastic parts. The DoEs had the following factors:

\section{Fixed Factors}

- Echo Time: $0.500 \mathrm{~ms}$

- Number of Echoes: 600

- Recycling Delay: $0.5 \mathrm{sec}$

\section{Variable Factors}

- Six OPPs

O 3 surveillance: 2,3 , and 1

o 3 newly molded: 4,5 , and 6

- Gain: $115 \mathrm{~dB}$

- Six chamber measurement locations: A, B, C, D, E, and F

\begin{tabular}{|c|c|c|c|c|c|c|}
\cline { 2 - 7 } \multicolumn{1}{c|}{} & \multicolumn{7}{c|}{ OPP Chamber Position } \\
\hline Study No. & A & B & C & D & E & F \\
\hline \hline 11 & 2 & 3 & 4 & 5 & 6 & 1 \\
\hline 12 & 3 & 4 & 5 & 6 & 1 & 2 \\
\hline 13 & 4 & 5 & 6 & 1 & 2 & 3 \\
\hline 14 & 5 & 6 & 1 & 2 & 3 & 4 \\
\hline 15 & 6 & 1 & 2 & 3 & 4 & 5 \\
\hline 16 & 1 & 2 & 3 & 4 & 5 & 6 \\
\hline
\end{tabular}

Table 1. Location of OPP by Number Within Chamber for DoE With Metal Parts 


\begin{tabular}{|c|c|c|c|c|c|c|}
\cline { 2 - 7 } \multicolumn{1}{c|}{} & \multicolumn{7}{c|}{ OPP Chamber Position } \\
\hline Study No. & A & B & C & D & E & F \\
\hline 22 & 1 & 2 & 3 & 4 & 5 & 6 \\
\hline 23 & 1 & 2 & 3 & 4 & 5 & 6 \\
\hline 24 & 1 & 2 & 3 & 4 & 5 & 6 \\
\hline 25 & 2 & 3 & 4 & 5 & 6 & 1 \\
\hline 26 & 3 & 4 & 5 & 6 & 1 & 2 \\
\hline 27 & 4 & 5 & 6 & 1 & 2 & 3 \\
\hline 28 & 5 & 6 & 1 & 2 & 3 & 4 \\
\hline 29 & 6 & 1 & 2 & 3 & 4 & 5 \\
\hline 30 & 7 & - & - & - & - & - \\
\hline 31 & 8 & - & - & - & - & - \\
\hline 32 & 9 & - & - & - & - & - \\
\hline 33 & 10 & - & - & - & - & - \\
\hline 34 & 11 & - & - & - & - & - \\
\hline 35 & 12 & - & - & - & - & - \\
\hline 36 & 13 & - & - & - & - & - \\
\hline 37 & 14 & - & - & - & - & - \\
\hline 38 & 15 & - & - & - & - & - \\
\hline 39 & 16 & - & - & - & - & - \\
\hline 40 & 17 & - & - & - & - & - \\
\hline 41 & 18 & - & - & - & - & - \\
\hline 42 & 19 & - & - & - & - & - \\
\hline 43 & 19 & - & - & - & - & - \\
\hline 44 & 20 & - & - & - & - & - \\
\hline
\end{tabular}

Table 2. Location of OPP by Number Within Chamber for DoE, Repeatability Study, and Comparison to Surveillance OPPs With Plastic Parts

\section{Outliers and Anomalies}

For reasons not completely understood, the level of noise and variation in distribution of signal/noise $(\mathrm{S} / \mathrm{N})$ ratios were much higher for studies $22-29$, especially for study 22 , than the previous DoE, studies 11-16 (Figure 6). The biexponential fit option within the software attempts to fit the CPMG data into a bi-exponential function and returns two time constants $\left(\mathrm{T}_{2} 1\right.$ and $\mathrm{T}_{2} 2$ ), their amplitudes (A1 and $\mathrm{A} 2$ ), and an offset. If only a single exponential function is found, it will return a time constant $\left(\mathrm{T}_{2}\right)$, its amplitude $(\mathrm{A})$ and raw data offset. If no fit is found or if the raw data is too weak, 0 or -1 will be returned as fitted results. Single exponential fitting will be applied if this option is de-selected.

$\mathrm{T}_{2}$ Error is a measure of the bi-exponential goodness of fit algorithm with lower numbers indicating a better fit of the data. In studies 11-16 with metal struts, only $269(0.86 \%)$ outliers out of 31,104 measurements were omitted from the analysis: $264 \mathrm{~T}_{2}$ Error $(\geq 1.3)$, four $\mathrm{T}_{2}=-1$, and one $\mathrm{T}_{2}=0$. The level of high $\mathrm{T}_{2}$ error values was much larger for the plastic part DoE and exhibited a bi-modal distribution (Figure 7). The only observable difference, besides the replacement of metal struts with plastic struts, was that the room temperature was as much as $10^{\circ} \mathrm{F}$ higher for most, if not all, of studies 22-29. Detailed temperature records were not kept for the room but the higher temperatures correlate with the HVAC system switching from summer 
cooling to winter heating. During previous discussion with Bruker Inc., it was noted that temperature changes as small as a couple of degrees Fahrenheit could affect the data measurements and lead to variation in measurements.

Using the same criteria to discard outliers from studies 11-16 for studies 22-29, the following $8,155(19.7 \%)$ outliers out of 41,472 measurements were omitted:

- $919(2.2 \%$ ) measurements (55 for OPP 4 at location D in study 22 and all 864 for OPP 1 at location $\mathrm{B}$ in study 29 ) were outliers and had poor $\mathrm{S} / \mathrm{N}$ ratios $\leq 16$. These outliers had poor regression fits that produced much higher $\mathrm{T}_{2}$ Error and spurious $\mathrm{T}_{2}$ values. Poor $\mathrm{S} / \mathrm{N}$ ratio behavior has been witnessed before when the minispec cable gets temporarily trapped between the probe and OPP. The 55 outliers at location D were limited to the lower right hand quarter of OPP 4 during the first rep which would be consistent with the cable getting briefly trapped. Although this may explain the low $\mathrm{S} / \mathrm{N}$ values, it does not explain the higher overall noise values for study 22 . The 864 outliers for OPP 1 indicate the cable may have been trapped during all three reps of the entire OPP. The cable being trapped for such a long measurement period spanning multiple reps has never been witnessed before.

- $12(0.03 \%)$ measurements were outliers and also were omitted: nine $\mathrm{T}_{2}=-1$, and three $\mathrm{T}_{2}=0$.

- Lastly, 7,224 (17.4\%) measurements were omitted: $26 \mathrm{~T}_{2}$ Error values ranging from 0 to 0.4 , and $7,198 \mathrm{~T}_{2}$ Error $\geq 1.3$. Graphs of the before condition and after omitting the outliers are shown in Figure 8. 

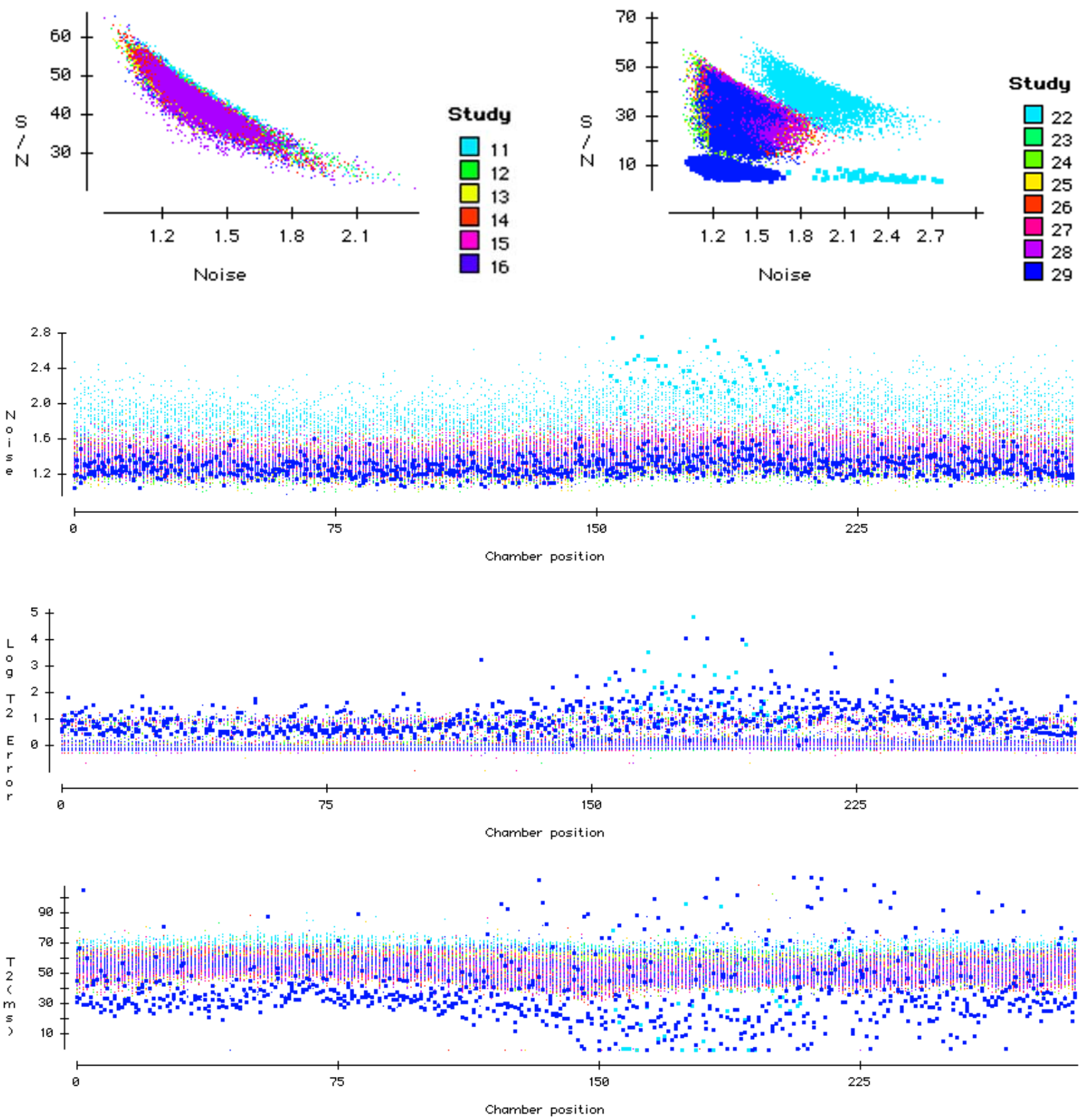

Figure 6. Plots Showing Bi-modal Distribution With Study 22 and Other Outliers Separated From the Other Studies. 881 (2.1\%) out of 41,472 measurements (55 for OPP 4 at location D in study 22 and all 864 for OPP 1 at location B in study 29, $11 T_{2}=0$ at random locations were outliers and had low signal-to-noise $(\mathrm{S} / \mathrm{N})$ ratios $\leq 16)$. Bold symbols show location of outliers and possible trapped cable. 


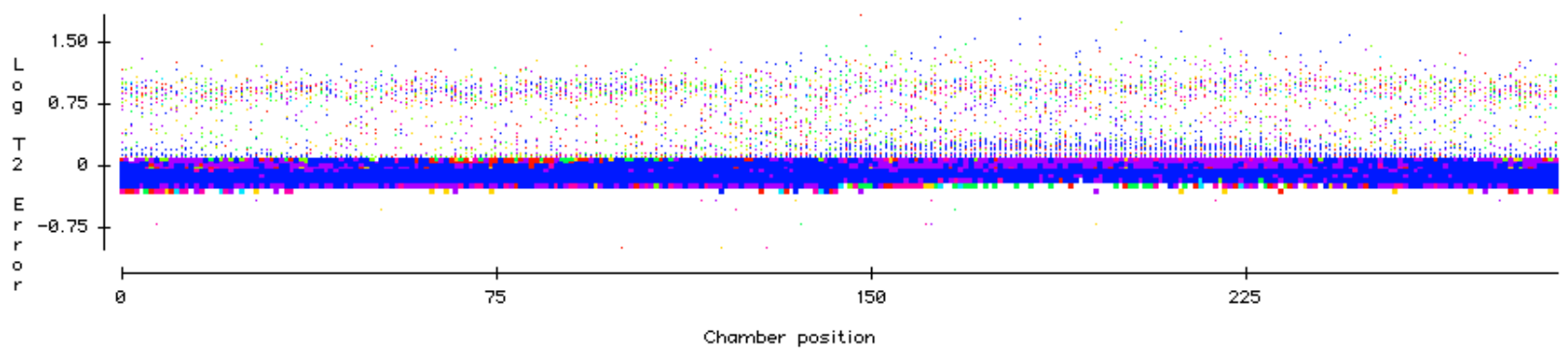

Figure 7. $\mathrm{T}_{2}$ Error Bi-Modal Distribution Showing 7,224 Outliers as Unbolded Symbols
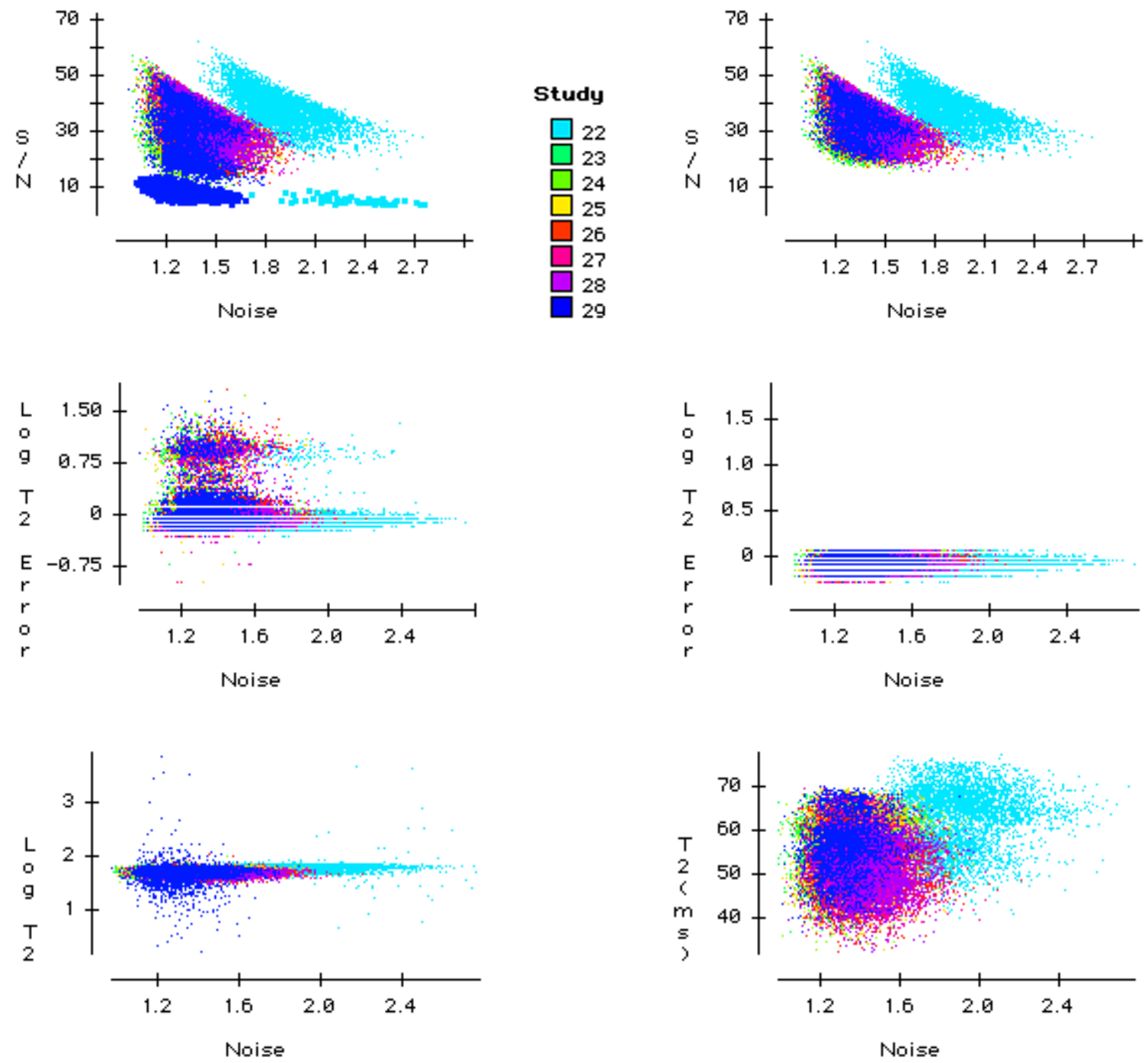

Figure 8. Graphs on the Right Show the Data set Remaining After Omitting 8,155 (19.7\%) Outliers 


\section{Repeatability Study Results With Plastic Parts}

Repeatability was evaluated by measuring OPPs in the same location 9 times over 3 separate study runs, studies 22-24 (Figures 9 thru 16). Between each study, the OPPs were removed from the chamber and replaced in the same location. The data show that study 22 was clearly very different than the subsequent two studies in terms of noise, therefore $T_{2}$ from study 22 and was omitted from the DoE statistical analysis. Study 22 was the first testing performed after installation of the plastic parts and study 23 began approximately a week after study 22 ended. The cause of this difference is unknown. Studies 23 and 24 had much more repeatable results but also are statistically distinguishable from each other.
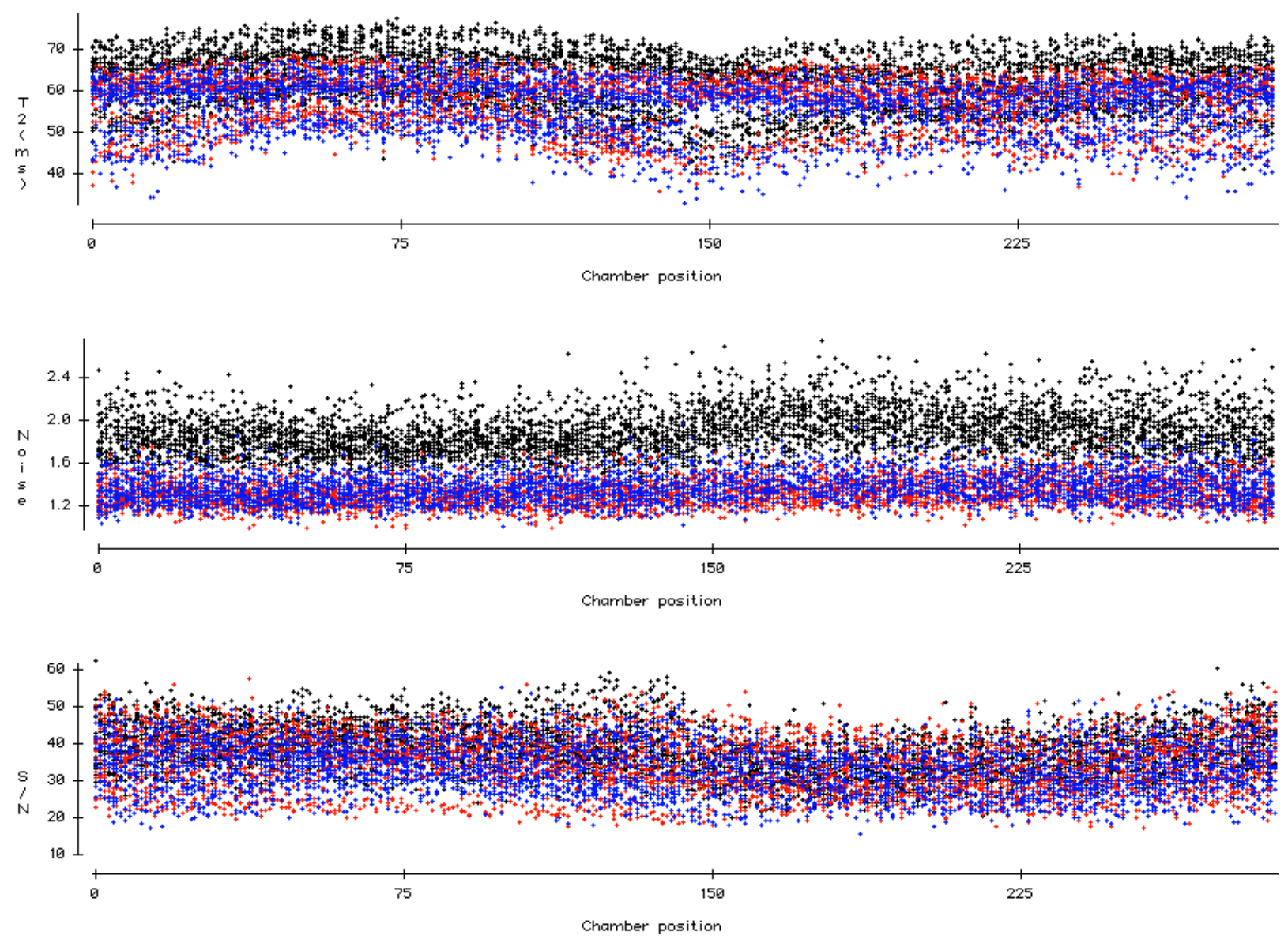

Figure 9. Repeatability Study Measurements With Outliers Omitted. These are black = study 22 (4,963 measurements), red = study 23 (4,238 measurements), and blue = study 24 (3,955 measurements). 


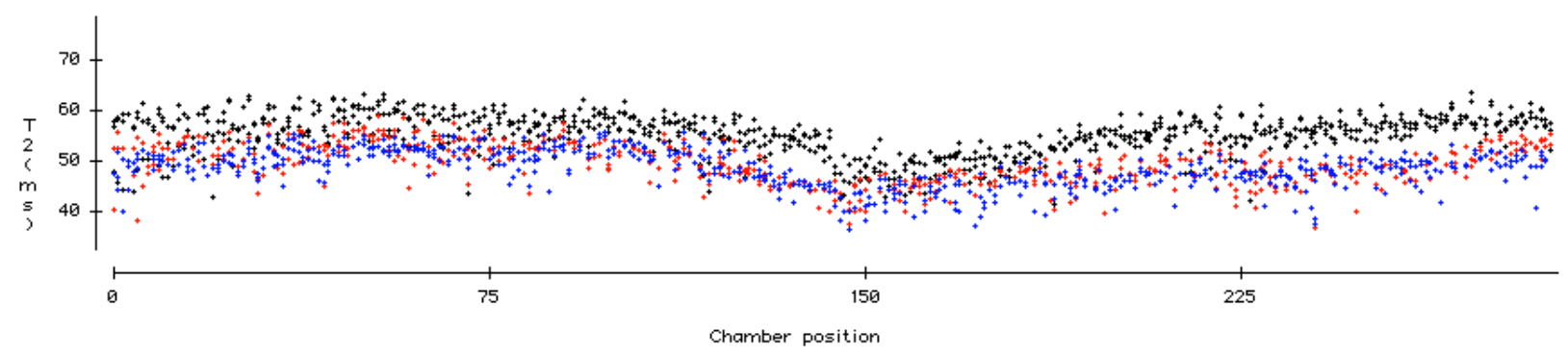

Figure 10. Repeatability Study Measurement of OPP 1 in Position A With Outliers Omitted. These are black = study 22, red = study 23, and blue = study 24 .

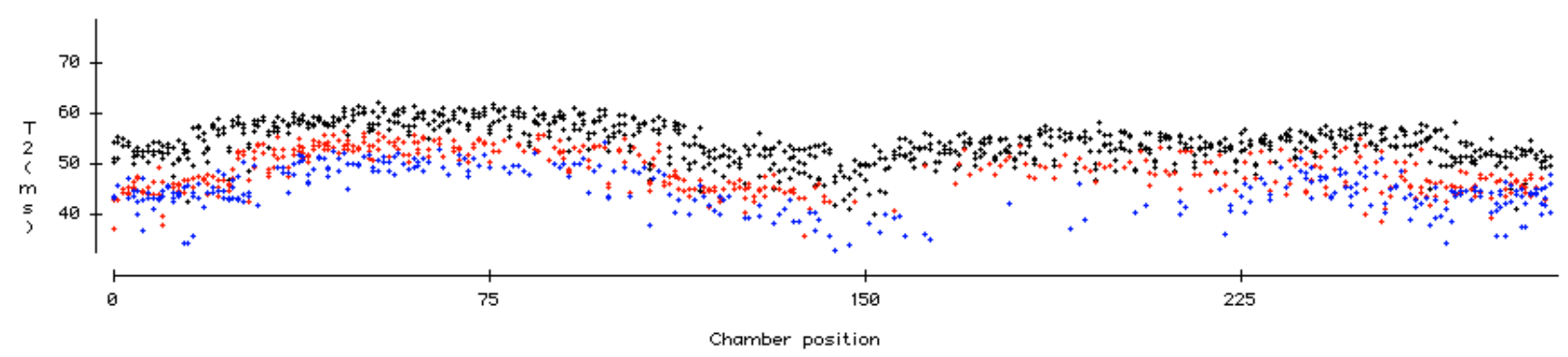

Figure 11. Repeatability Study Measurements of OPP 2 in Position B With Outliers Omitted. These are black = study 22, red = study 23, and blue = study 24.

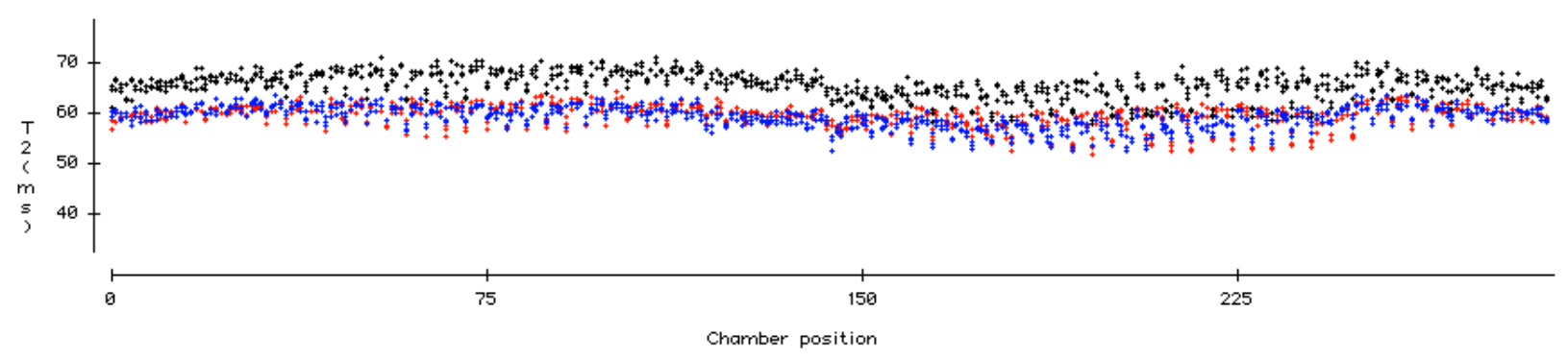

Figure 12. Repeatability Study Measurements of OPP 3 in Position C With Outliers Omitted. These are black = study 22, red = study 23, and blue = study 24.

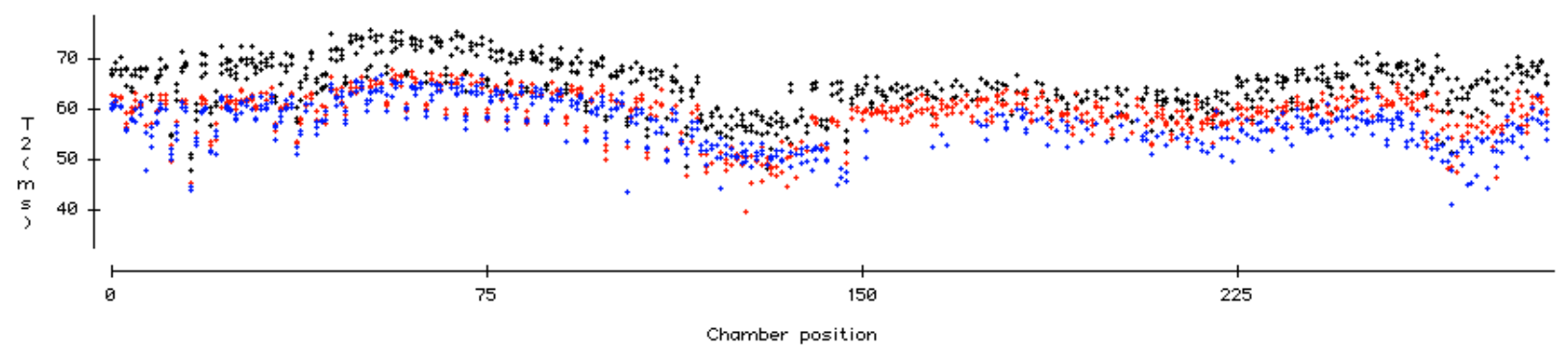

Figure 13. Repeatability Study Measurements of OPP 4 in Position D With Outliers Omitted. These are black = study 22, red = study 23, and blue = study 24. 


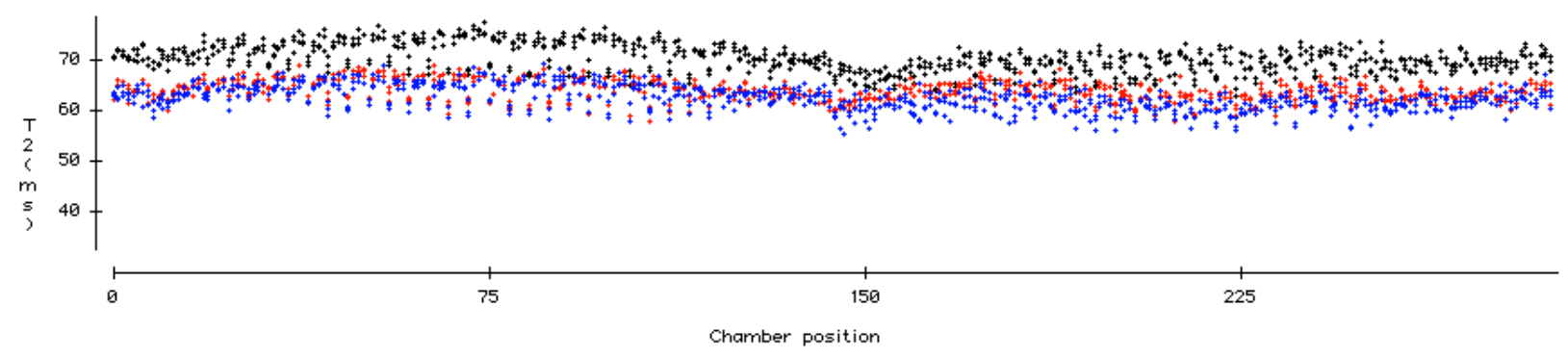

Figure 14. Repeatability Study Measurements of OPP 5 in Position E With Outliers Omitted. These are black = study 22, red = study 23, and blue = study 24.

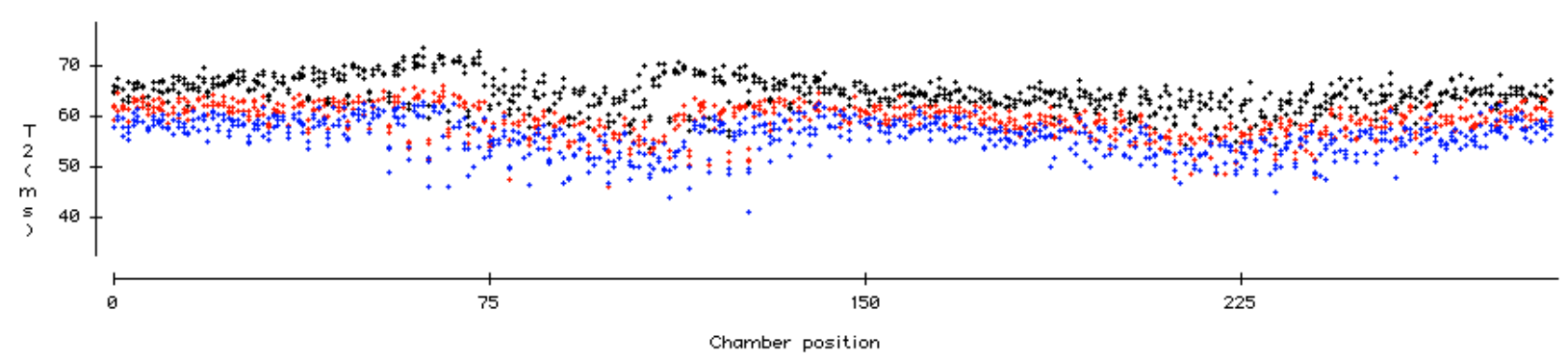

Figure 15. Repeatability Study Measurements of OPP 6 in Position F With Outliers Omitted. These are black = study 22, red = study 23, and blue = study 24.
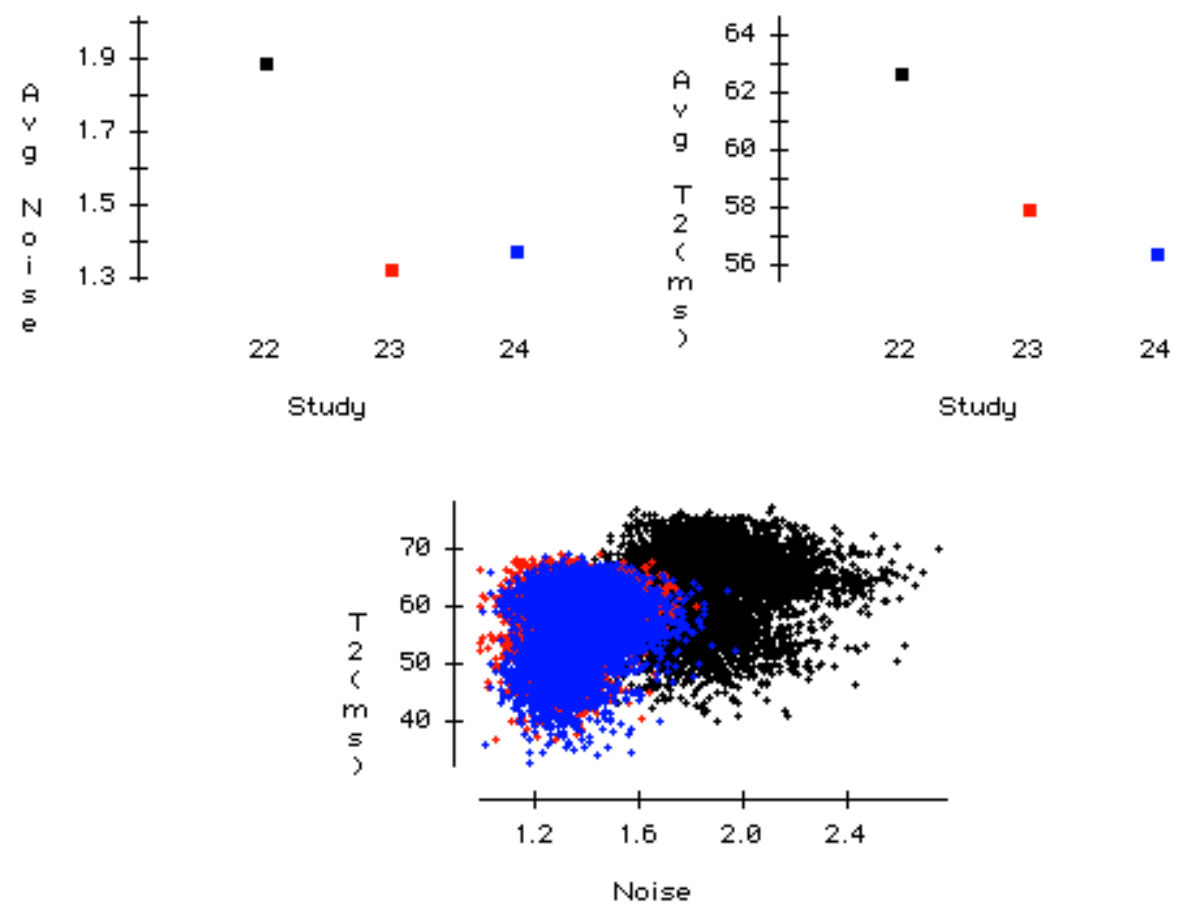

Figure 16. Repeatability Studies With Outliers Omitted Showing Average Values and Relationships 


\section{DoE Results Comparing Effect of Replacing Metal Parts with Plastic Parts}

The statistical analysis of the DoE comprised 28,354 measurements from studies 23-29. Replacing the metal struts with plastic struts had a strong effect and eliminated the noise interference pattern observed at the front of the chamber in the previous DoE (Figure 17).
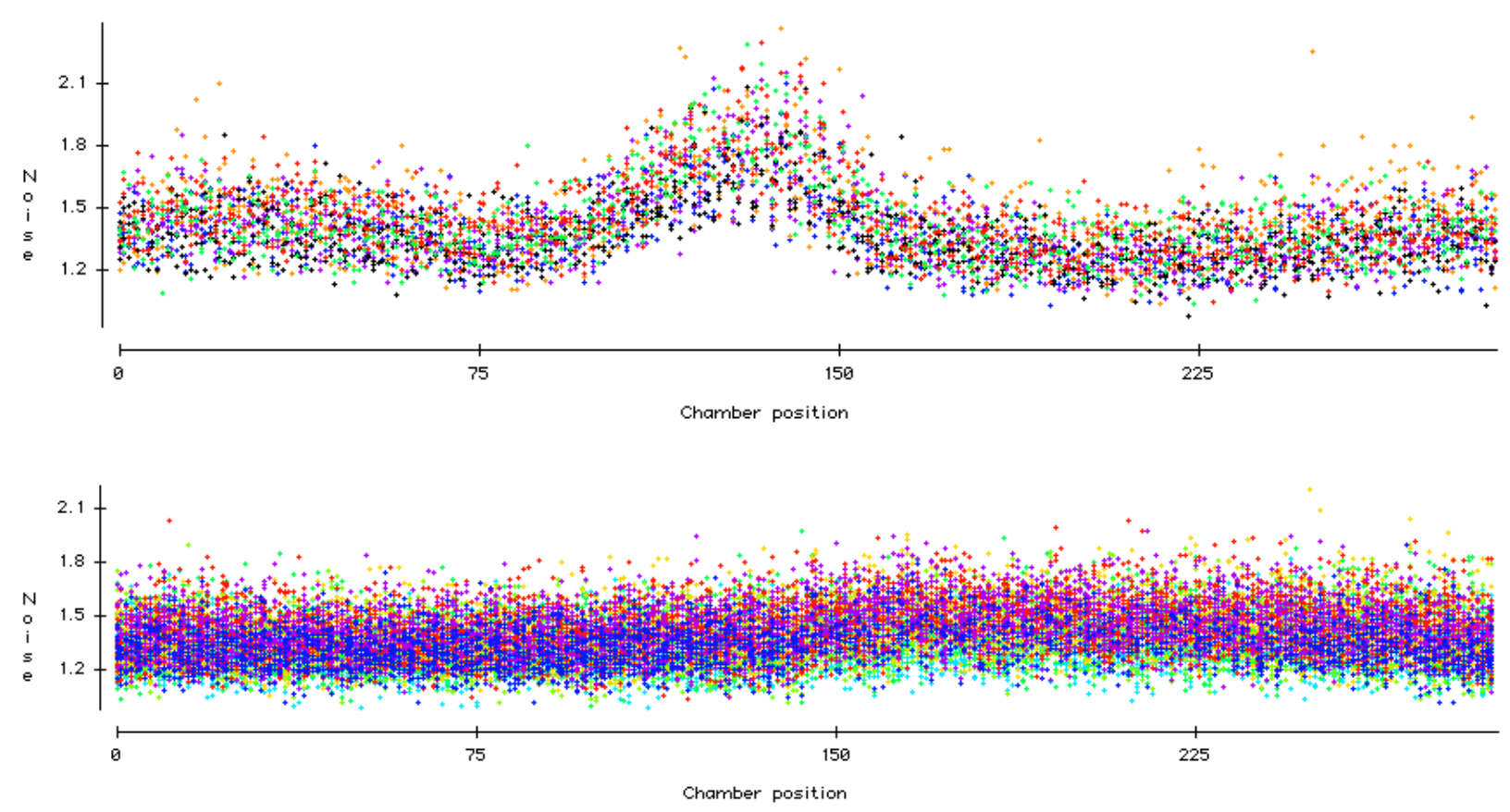

Figure 17. Noise Correlation With Chamber Location for all OPPs Showing Reduction in Noise at Position A After Replacing Metal Struts With Plastic Struts. Top graph shows adverse effect of metal parts at Position A for studies 11-16. Bottom graph shows better noise uniformity for all positions A-F in studies 23-29.

Figure 18 graphically depicts the effect on measurements by switching to plastic parts. The plastic parts affected all relationships for all of the measurements. One significant change is the trend in higher noise from front to back, which is the opposite of the noise trend with the metal parts previously observed. The $\mathrm{S} / \mathrm{N}$ ratio is now significantly lower and chamber positions to the right have lower $\mathrm{S} / \mathrm{N}$ relative to chamber positions on the left (Figure 19). $\mathrm{T}_{2}$ values also were lower and the values in chamber positions to the right measure lower relative to chamber positions on the left (Figures 20-22). 

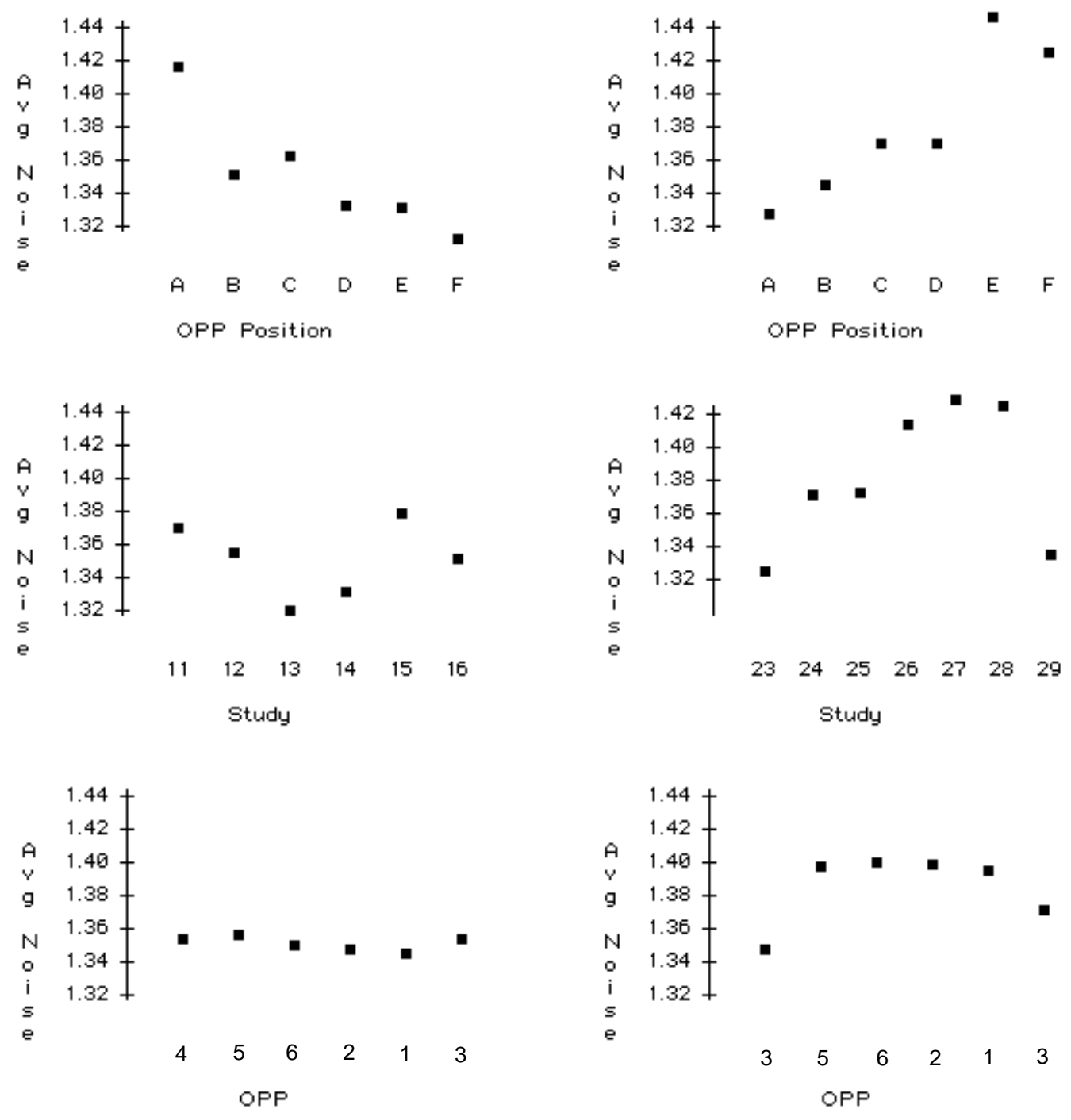

Figure 18. Noise Correlation for all OPPs in Chamber. Graphs on left are from studies 11-16 and graphs on right are from studies 23-29. 

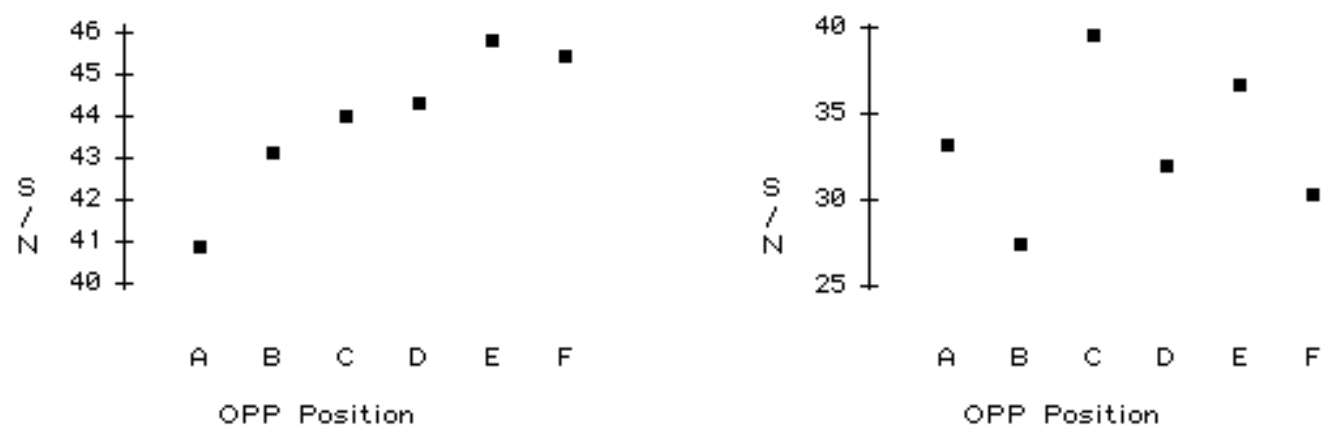

Figure 19. Results for all OPP Property Averages by OPP Location in Chamber. Graphs on left are from studies 11-16 and graphs on right are from studies 23-29. All S/N values are shifted lower and chamber positions to the right now measure lower relative to chamber positions for plot on the left. 

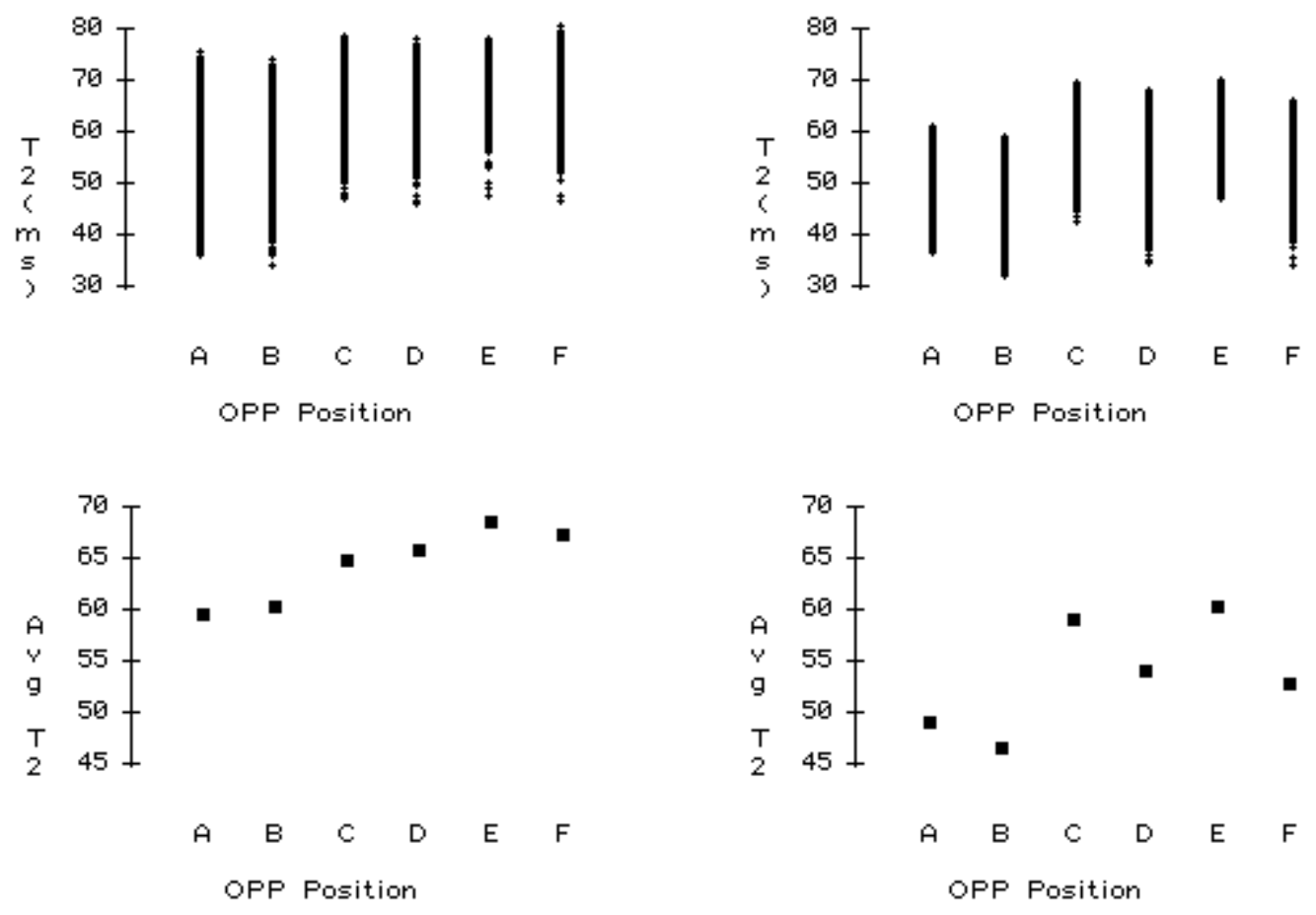

Figure 20. $\quad \mathrm{T}_{2}$ Correlation for all OPPs in all Locations in Chamber by Study. Graphs on left are from studies 11-16 and graphs on right are from studies 23-

29. 

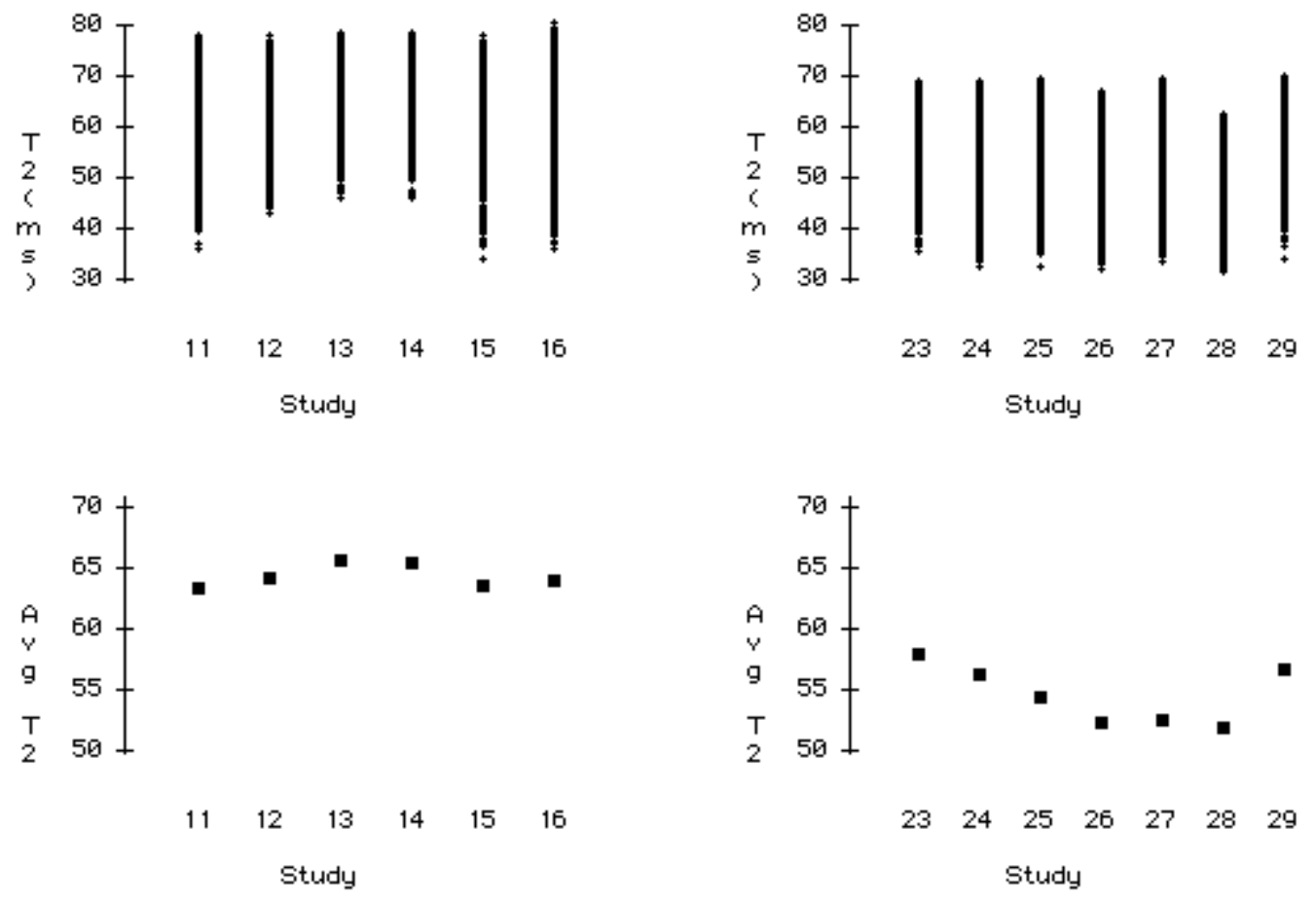

Figure 21. $\quad \mathrm{T}_{2}$ Correlation for all OPPs in all Locations in Chamber by Study. Graphs on left are from studies 11-16 and graphs on right are from studies 2329. Ideally, average data should approximate a horizontal line showing little to no instrument drift. Data on right from plastic part studies displays larger variation and all measurements have been shifted lower. 

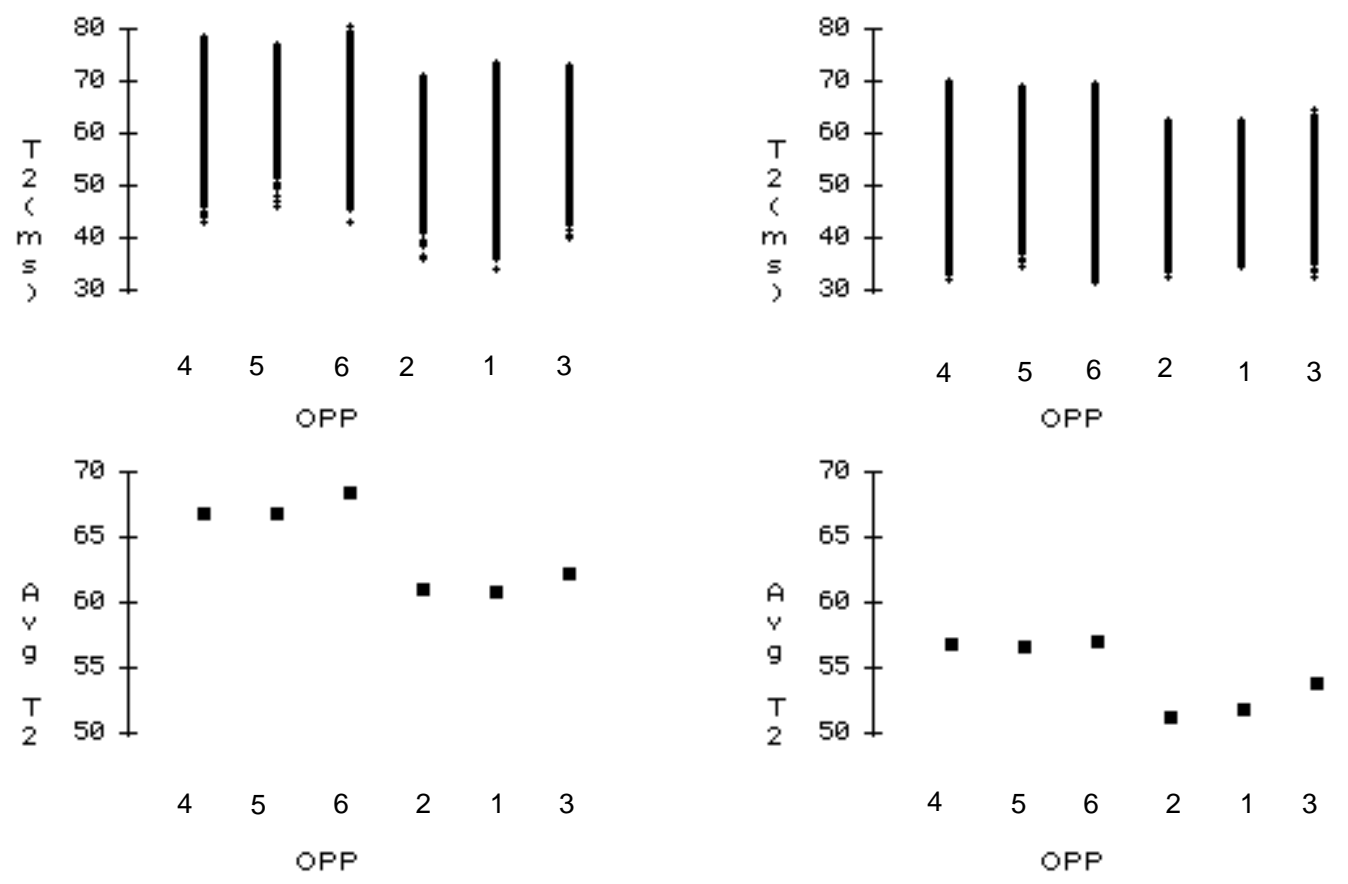

Figure 22. $\quad \mathrm{T}_{2}$ Correlation for all OPPs in all Locations in Chamber by OPP. Graphs on left are from studies 11-16 and graphs on right are from studies 23-29. Data shows slightly lower $T_{2}$ values for aged OPPs.

\section{Surveillance Versus New OPPs}

Thirty-one OPPs were molded in November 2005 as a part of process prove-in (PPI) activities. Ten of these parts were compared with 11 OPPs from surveillance (Table 2). Each OPP was measured in location A to minimize variation caused by chamber position in order to determine any $\mathrm{T}_{2}$ correlation with OPP age.

A total of 19,008 measurements on 21 OPPS were taken by the previously described method with 3 replicates for each measurement location. 1,666 (8.8\%) outliers were omitted leaving 17,344 measurements. Measurements with $\mathrm{T}_{2}$ error values $>3.8$ were arbitrarily chosen to be omitted based on the visual distribution appearance of the data (Figures 23 and 24). Although the plastic parts caused a reduction in variation, localized interference is still apparent (Figure 25). 

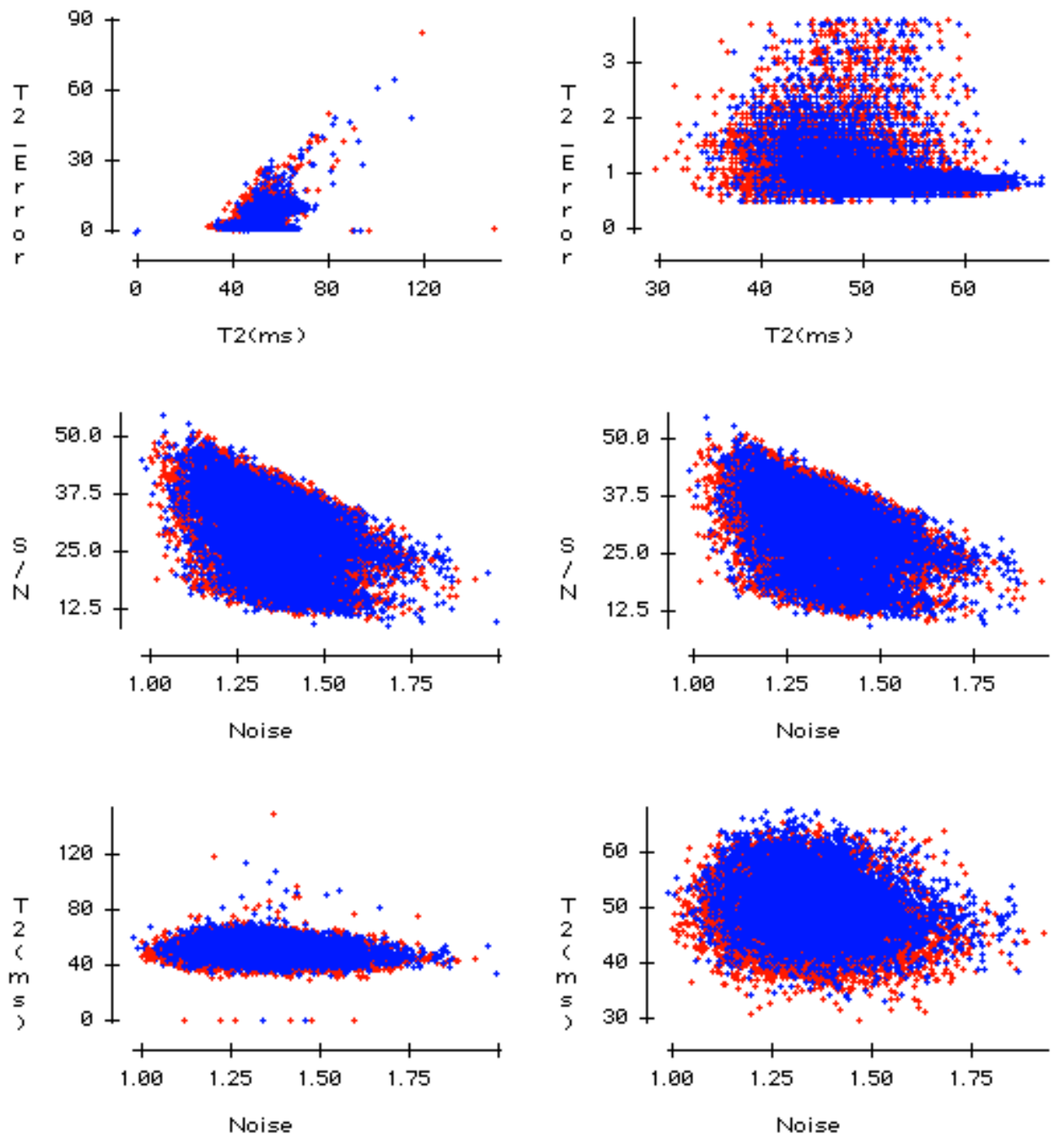

Figure 23. Correlation for all OPPs in Location A in Chamber. Graphs on the right show the data set remaining after omitting 1,666 (8.8\%) outliers. Blue symbols denote new OPPs and red symbols denote surveillance OPPs. 

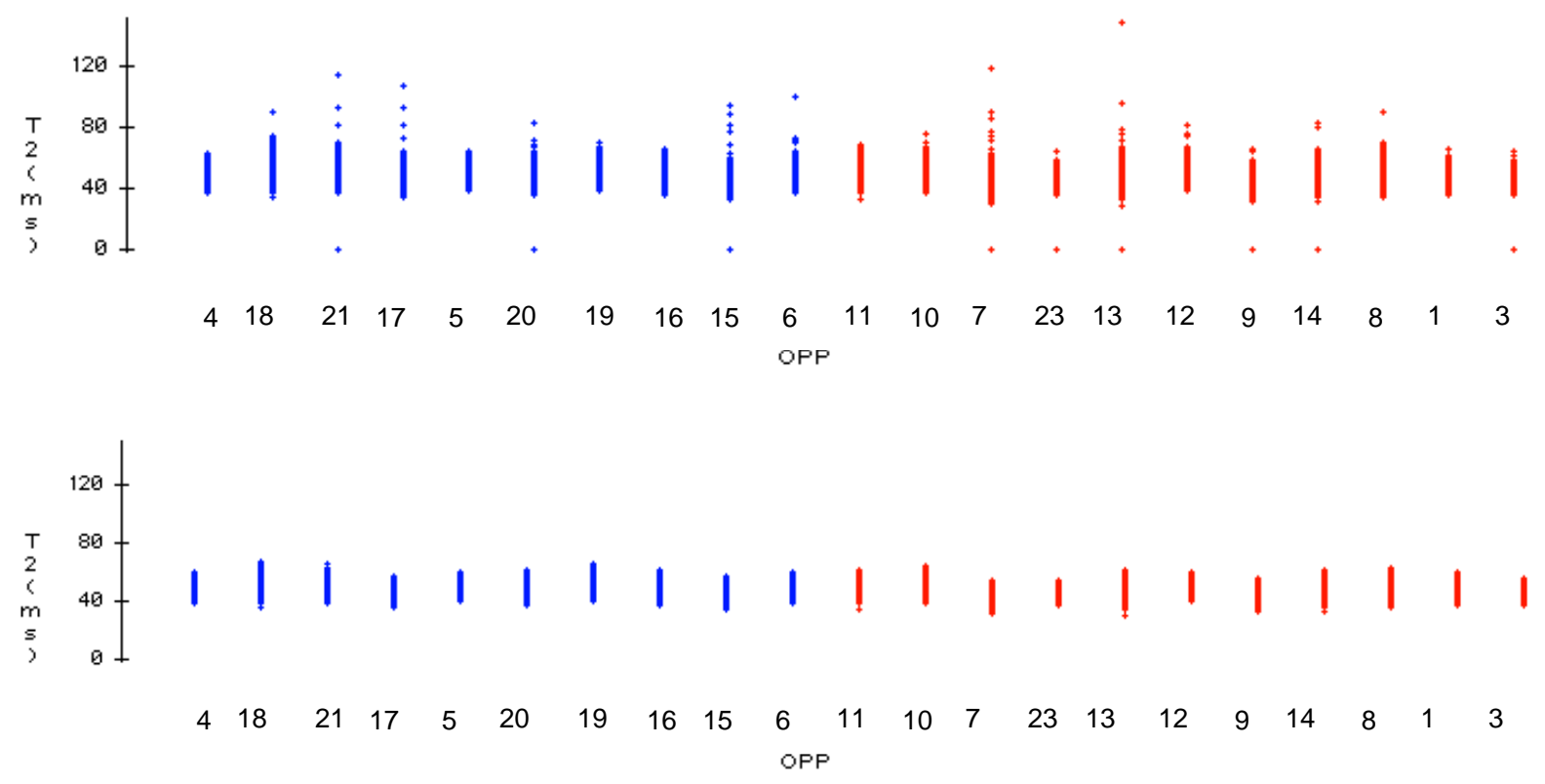

Figure 24. Correlation for all OPPs in Location A in Chamber. Graph on the bottom shows the data set remaining after omitting 1,666 (8.8\%) outliers. Blue symbols denote new OPPs and red symbols denote surveillance OPPs.

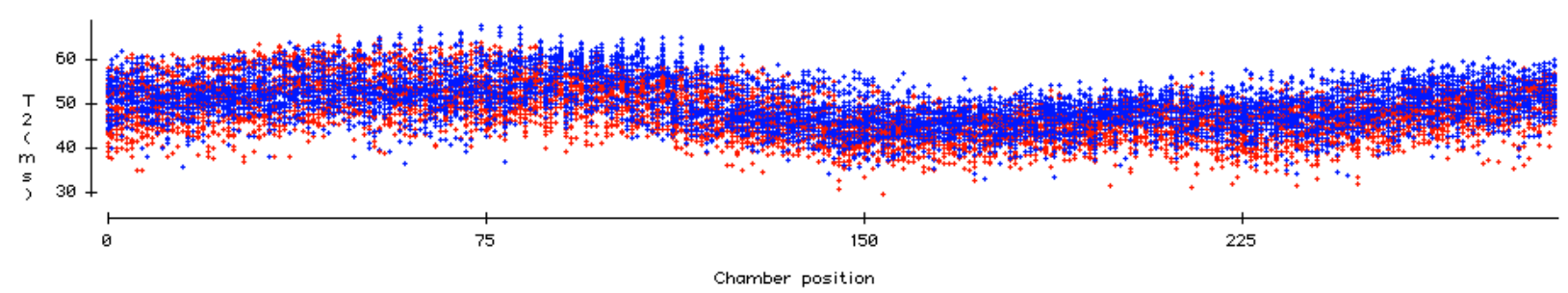

Figure 25. $\mathrm{T}_{2}$ Values for all OPPs in Location A With Outliers Omitted. Blue symbols denote new OPPs and red symbols denote surveillance OPPs. Consistent broad wave pattern distribution across all OPPs indicates continuing effects of local chamber measurement environment on $T_{2}$ after the installation of plastic parts.

The age at disassembly for all but one of the surveillance OPPs was provided by LLNL. A comparison of the newly molded PPI parts with the OPPs returned from surveillance show no statistically significant difference in $\mathrm{T}_{2}$ measurements averaged over the entire OPP surface. Consequently, no measurable degradation in average crosslink density with age is discernable using the Profiler (Figure 26). 


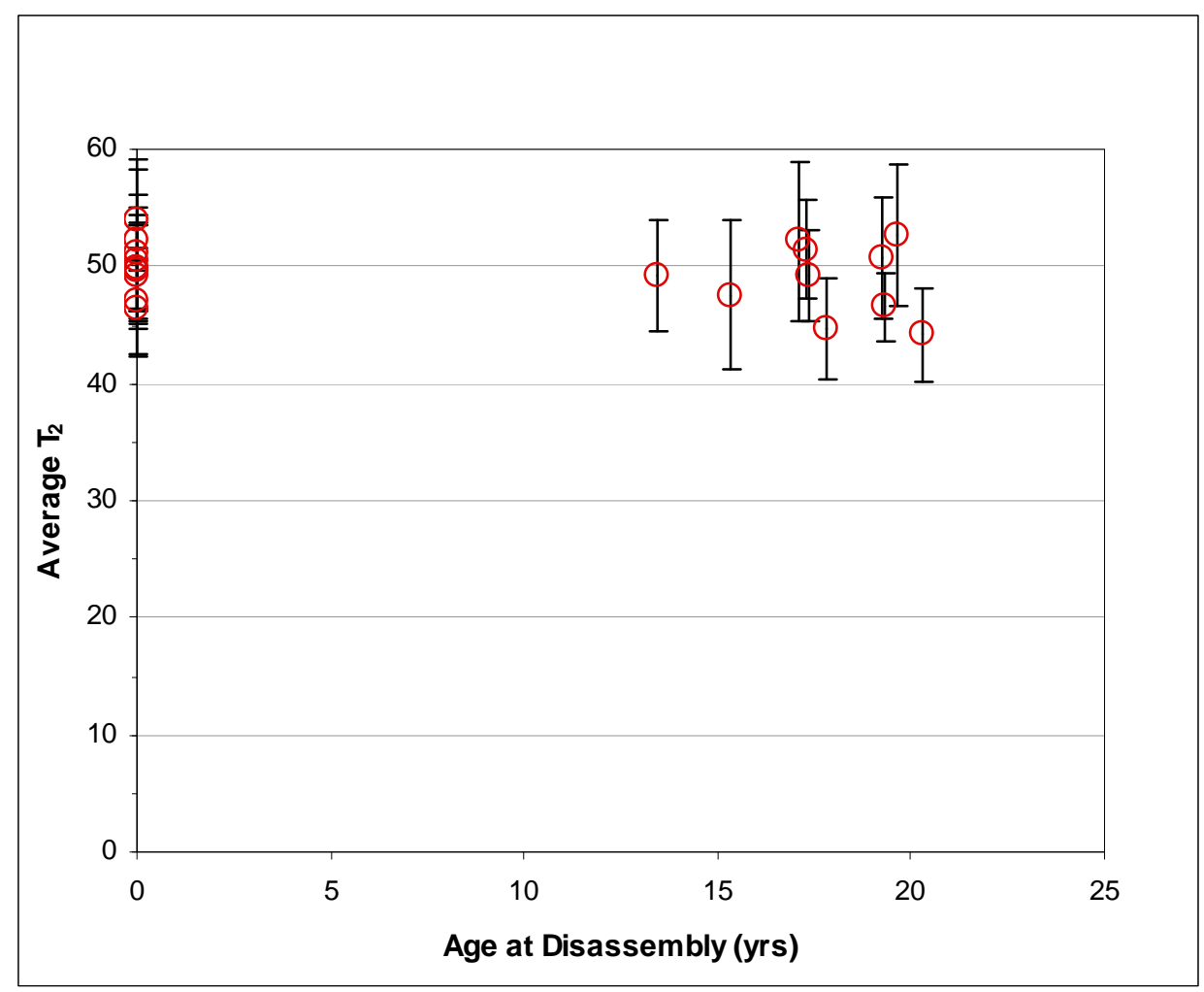

Figure 26. Correlation of Average $T_{2} \pm \sigma$ With age for new and Surveillance OPPs. $T_{2}$ units are $m s$.

\section{Cellular Silicone Parameter DoE}

A cellular silicone sample, approximately $8 \mathrm{~mm}$ thick by $55 \mathrm{~mm}$ in diameter, was measured to determine preferred minispec ProFiler parameters based on a DoE evaluation (Table 3 ). Three replicates were measured per condition (Figure 27). Fifteen additional replicates were performed for certain of the higher scan rates at 115 Gain because of high $\mathrm{T}_{2}$ error values. Of 123 measurements, 27 (22\%) outliers were omitted. Many of the outliers can be traced to adverse measurement effects at the sample edge. 


\begin{tabular}{|l|c|c|c|c|}
\hline \multicolumn{1}{|c|}{ Factor } & Number of Levels & Level 1 & Level 2 & Level 3 \\
\hline \hline Gain & 2 & 115 & 119 & - \\
\hline Number of scans & 3 & 128 & 512 & 1024 \\
\hline Number of echoes & 2 & 500 & 600 & - \\
\hline Echo time (ms) & 3 & 0.44 & 0.50 & 0.60 \\
\hline
\end{tabular}

Table 3. Details of DoE for Parameter Optimization
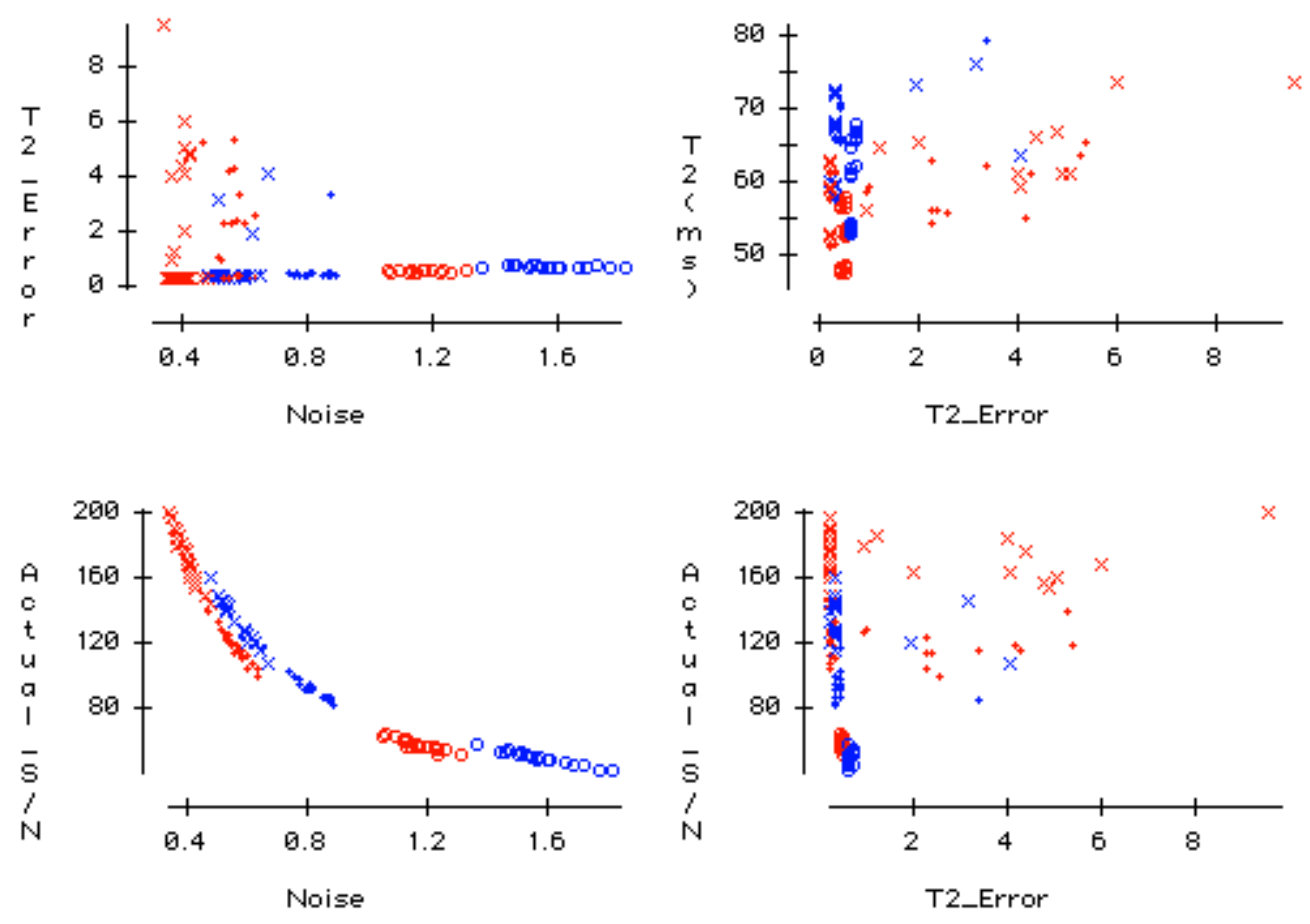

Figure 27. Response Results for Cellular Silicone Parameter DoE. Red symbols are 115 Gain and blue symbols are 119 Gain. Number of scans are symbolized as follows: 0 is 128," is 512, and $x$ is 1024. 

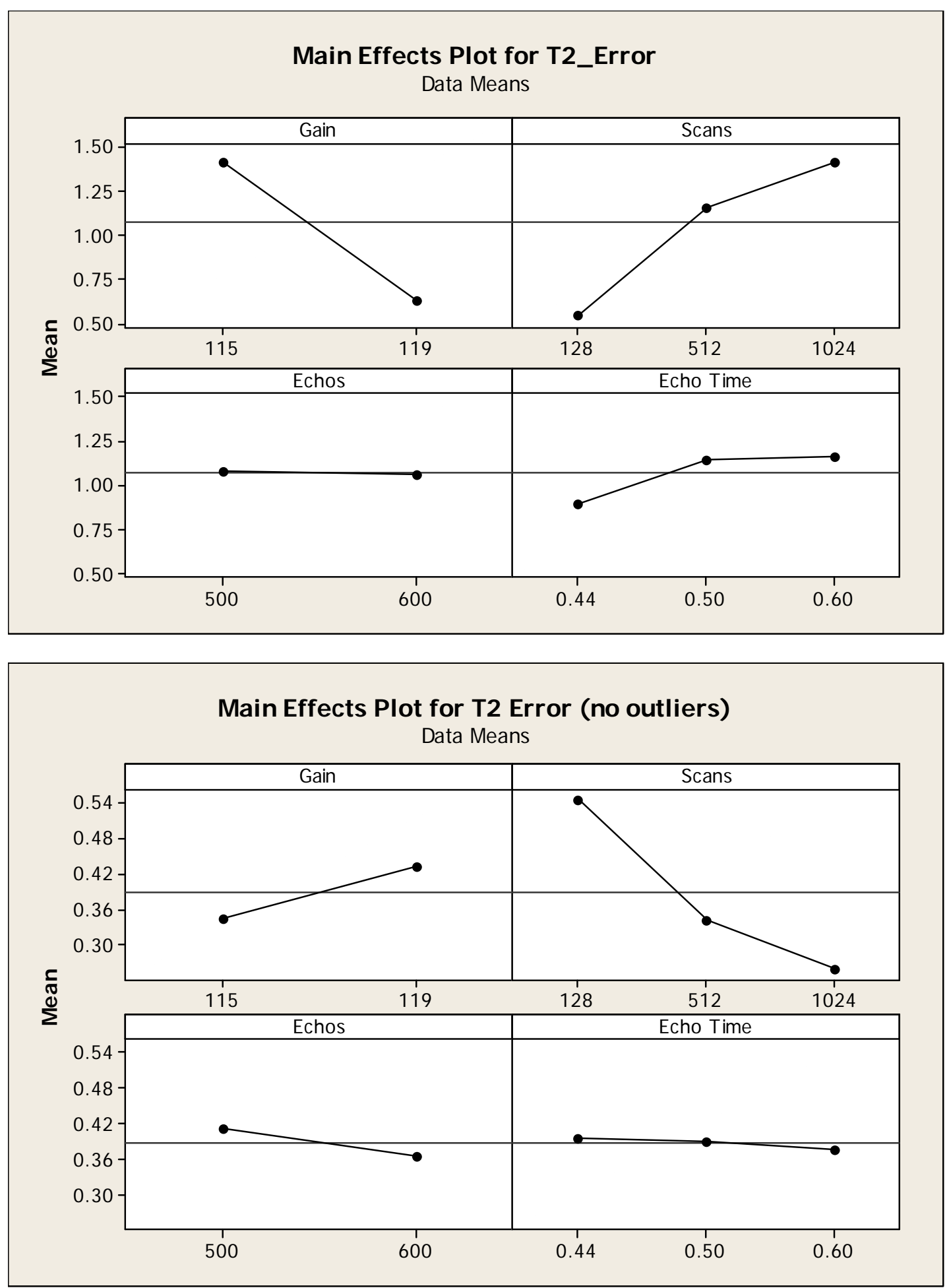

Figure 28. $\quad \mathrm{T}_{2}$ Error Response Results for Cellular Silicone Parameter DoE. Top graph shows analysis of all data; only Gain had a statistically significant effect $(\alpha=0.05$ level). Bottom graph is a reanalysis after omitting the outliers; all of the effects are statistically significant. 

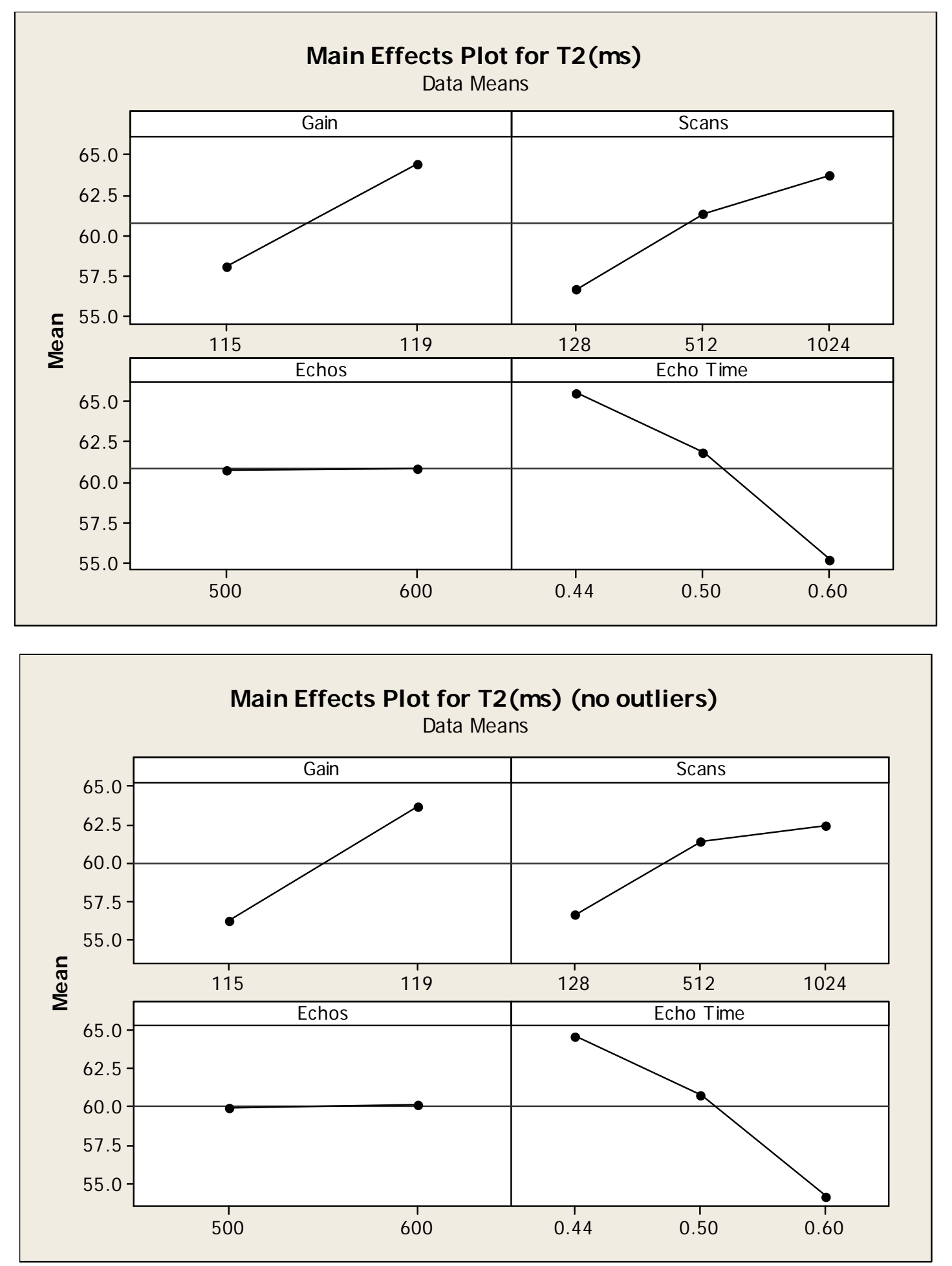

Figure 29. $\quad T_{2}$ Response Results for Cellular Silicone Parameter DoE. Top graph shows analysis of all data and bottom graph is a reanalysis after omitting the outliers; only number of echoes did not have a statistically significant effect ( $\alpha=0.05$ level). Omitting the outliers had a negligible effect on the average $T_{2}$ value. All parameters except number of echoes were statistically significant. 
The following parameters were chosen for the cellular silicone sample to provide a balance between test speed, accuracy, and reduced potential for outliers:

\author{
Gain:119 \\ Number of scans: 128 \\ Number of echoes: 500 \\ Echo time: $0.5 \mathrm{~ms}$ \\ Recycle Delay: 0.5
}

\title{
Cellular Silicone Measurement Results
}

The cellular silicone sample was measured using the settings determined from the parameter DoE study. Four replicate measurements were performed at each of 169 locations separated from each other by $5 \mathrm{~mm}$ (Figure 30). The minispec probe measurement area is large relative to the cellular silicone sample area which resulted in higher variation and much lower $\mathrm{T}_{2}$ values when the minispec probe was near the edge of the sample (Figure 31). As observed in previous studies, the measurement response is somewhat asymmetric and is off center slightly to the left of the minispec probe's center line which shifts the contour plot $5 \mathrm{~mm}$ to the right.

Measurement locations affected by the edge were omitted leaving 50 locations for analysis (Figures 32 and 33). The data is generally very uniform in the center of the sample but there are areas of statistically significant differences between high and low $\mathrm{T}_{2}$ regions. Nevertheless, it is not possible to determine if the cause of these differences are variation in crosslink density or variations in material density since the minispec is sensitive to both. Because the range of average $T_{2}$ values was less than approximately $3 \mathrm{~ms}$ though, the magnitude of difference in either underlying property is considered negligible. 

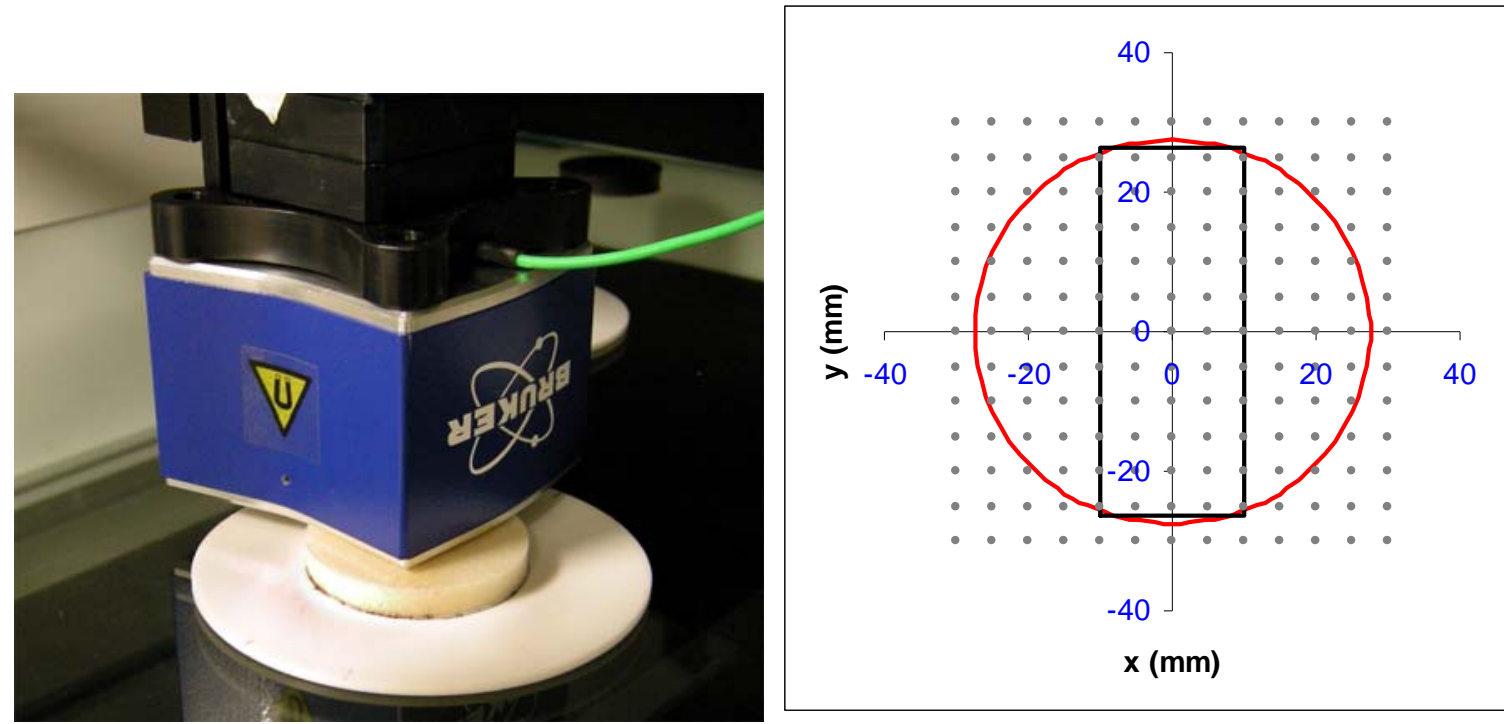

Figure 30. Cellular Silicone Sample Between ProFiler and the OPPs Polyethylene Centering Fixture. The circle shows the location of cellular silicone sample. Dot symbols represent the measurement locations centered within the minispec probe's measurement area. The rectangle shows the measurement boundaries of the probe's ceramic window centered at location number $84(0,0)$.


Figure 31. $\quad \mathrm{T}_{2}$ Value Contour Plot of Cellular Silicone Sample Showing Edge Effects for Scan Pattern in Graph on Right 


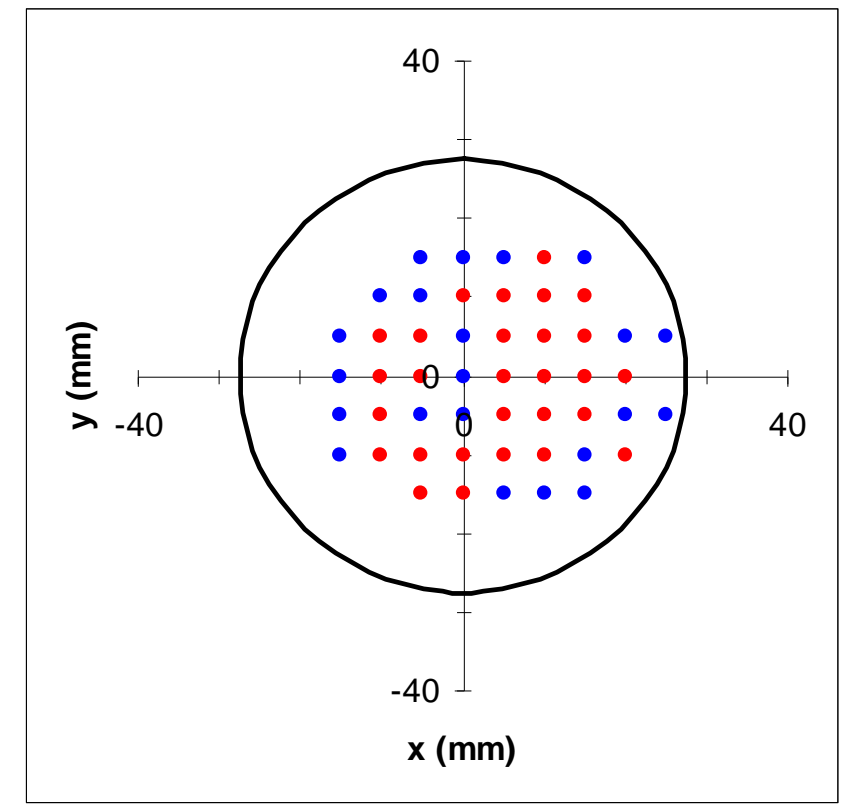

Figure 32. Circle Shows the Location of the Cellular Silicone Sample. The dot symbols show the minispec probe measurement pattern after removing outliers caused by edge effects. The average of the 50 locations was $57.5 \mathrm{~ms}$. The red dot symbols have average $T_{2}$ values 57.5-58.9 and the blue dot symbols have average $T_{2}$ values 56.3-57.5.
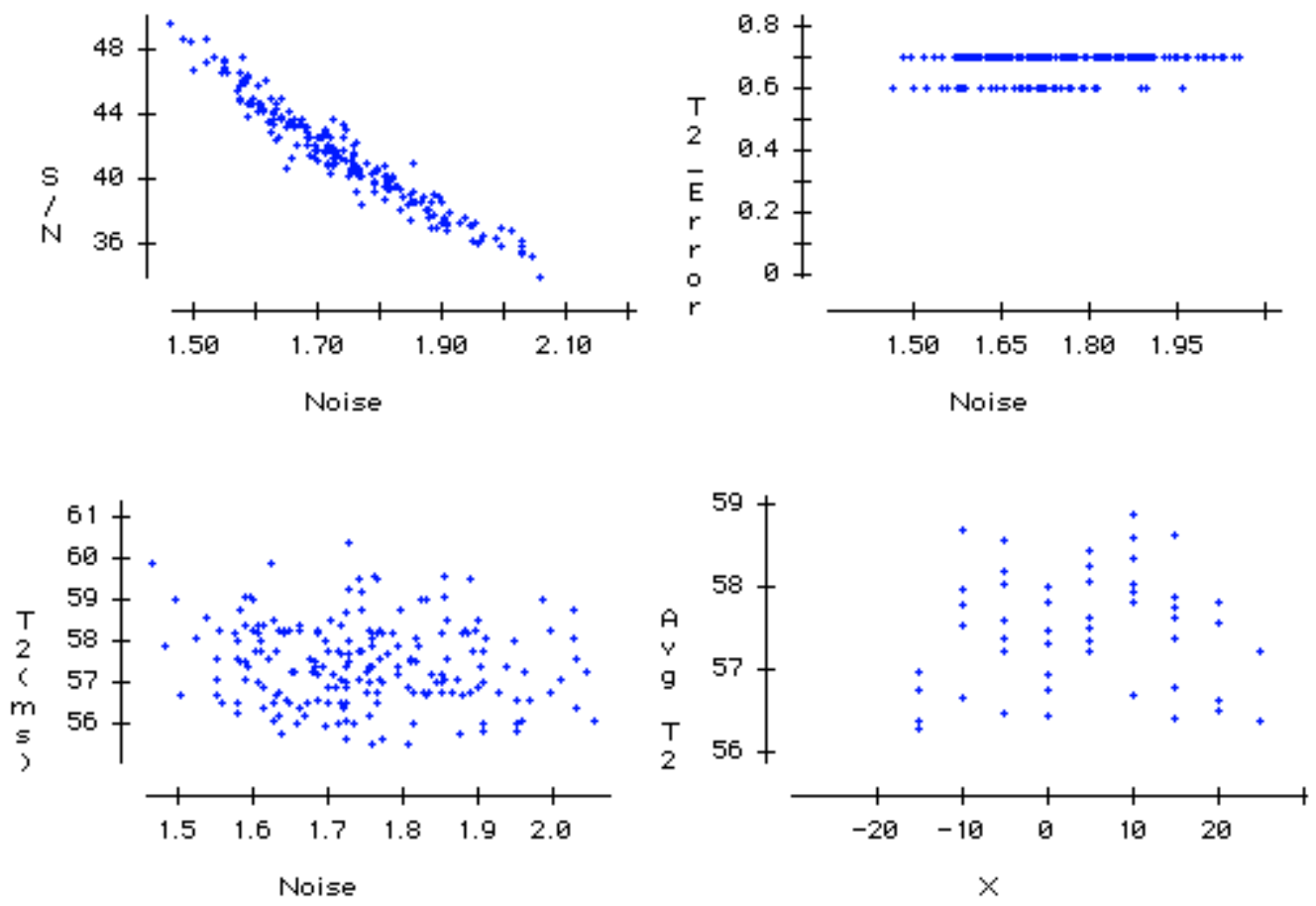

Figure 33. Plots of Various Minispec Response Variables for Locations in Figure 32 


\section{Conclusions}

The repeated DoE discovered that replacing the metal parts with plastic parts had a strong effect and eliminated the major noise interference patterns observed in the previous DoE study. Nevertheless, the level of overall variation is still relatively large. The observed variation in measurement responses limits the instrument's capability to primarily detecting any combination of large internal voids or grossly undercured areas that contain $<50 \%$ of the recommended catalyst level. More importantly, whereas the ProFiler can detect large differences in crosslink density in slab data, it appears the level of age-related changes in OPP crosslink density has not progressed enough and are below the detection limit of the present configuration. Thus, the current ProFiler system is not recommended for use as a non-destructive surveillance test method for the OPPs.

The ProFiler may still be a suitable tool for other types of material and the cellular silicone sample results showed good repeatability considering the larger sample thickness and after eliminating known adverse edge effects. Significant challenges would have to be overcome to measure samples with curved surfaces or unusual shapes in order to mitigate the kind of variation seen in these studies due to the amount of material in the measurement field and its relative proximity to the ProFiler's surface. 


\section{Accomplishments}

54,275 measurements were performed during various screening tests and a DoE to determine the effect of OPP position on $\mathrm{T}_{2}$ value within the measurement chamber of a new automated minispec ProFiler NMR system. In addition, a cellular silicone sample also was evaluated. This report documents the results.

\section{Future Work}

Other materials may show more potential for analysis than the current DC745 material and should be studied. Design modifications that include a stronger magnet have potential to increase $\mathrm{S} / \mathrm{N}$ and depth of penetration. Also, a robotics system that can orient a sample as needed relative to a fixed ProFiler may produce significant improvements by decreasing measurement variation. 


\section{References}

1. M. H. Wilson; Evaluation Of Automated Low-Field NMR Relaxometry For Analysis Of Polymers, FY08 Topical Report on Enhanced Surveillance Program 708094.

UNCLASSIFIED. Kansas City Division: KCP-613-8531, November (2008).

2. Sarah C. Chinn, Angela Cook-Tendulkara, Robert Maxwell, Hilary Wheeler, Mark Wilson, Z. Harry Xie, Qualification Of Automated Low-Field NMR Relaxometry For Quality Control Of Polymers In A Production Setting, Polymer Testing (2007) 26:1015-1024.

3. S. Meiboom, D. Gill; Modified Spin-Echo Method For Measuring Nuclear Relaxation Times, Rev Sci Instrum (1958) 29:688.

4. Richard J. Pazur and F. J. Walker; State of Cure Measurements in Peroxide and Sulfur Cured EPDM, Rubber World Aug. 2009, 5.4:25-34.

5. Julie L. Herberg, Sarah C. Chinn, April M. Sawvel, Erica Gjersing, Robert S. Maxwell; Characterization Of Local Deformation In Filled-Silicone Elastomers Subject To High Strain - NMR MOUSE and Magnetic Resonance Imaging As A Diagnostic Tool For Detection Of Inhomogeneities, Polymer Degradation and Stability (2006) 91:1701-1710. 